\title{
Human and natural drivers of the recent contrasting trends between daytime and nighttime hot extremes
}

Sang-Wook Yeh ( $\nabla$ swyeh@hanyang.ac.kr)

Hanyang University

\section{Eun-Hye Lee}

Hanyang University

\section{Seung-Ki Min}

Pohang University of Science and Technology https://orcid.org/0000-0002-6749-010X

Article

Keywords: extreme heat events, heat waves, tropical night

Posted Date: January 19th, 2021

DOI: https://doi.org/10.21203/rs.3.rs-36271/v1

License: (c) (1) This work is licensed under a Creative Commons Attribution 4.0 International License.

Read Full License 


\title{
Human and natural drivers of the recent contrasting trends
}

\section{between daytime and nighttime hot extremes}

\author{
Sang-Wook Yeh ${ }^{1}$, Eun-Hye Lee ${ }^{1}$, and Seung-Ki Min²
}

${ }^{1}$ Department of Marine Sciences and Convergence Technology, Hanyang University, Ansan, South Korea.

${ }^{2}$ Division of Environmental Science and Engineering, Pohang University of Science and Technology, Pohang, South Korea.

\section{Submitted to Nature Communication}

The frequency and duration of extreme heat events, including heat waves (HWs, daytime hot extremes) and tropical night (TNs), are increasing significantly as the climate warms, adversely affecting human health, agriculture, and energy consumption. Although many detection and attribution studies have examined extreme heat events, the underlying mechanisms associated with the recent increase in HWs and TNs remain unclear. In this study, we analyze the controlling factors behind the distinct increases in HW and TN events over the Northern Hemisphere during boreal summer (June to August). We found that the occurrence of HW events has been increasing gradually since 1980, mostly due to anthropogenic forcing. However, the occurrence of TN events increased abruptly during the late 1990s and has changed little since then. We demonstrate that this sudden increase in TN events is closely associated with low frequency variability in sea surface temperature, including the Pacific Decadal Oscillation, indicating its natural origin. We further found that CMIP5 climate models fail to capture the observed non-linear 
increases in TN events, implying potentially large uncertainty in future projections of

nighttime heat events and its impacts on human society and ecosystem.

The Earth's global average surface temperature has been gradually increasing since 1880; most of the hottest years observed have been since $2010^{1}$, and those changes are found to be mainly caused by an increase in the greenhouse gas concentration from the pre-industrial period. Along with the increase in surface temperature, extreme weather events such as heat waves (HWs, daytime hot extremes), tropical nights (TNs, nighttime hot extremes), floods, and intense typhoons have occurred with increased frequency in the past few decades ${ }^{2-5}$. In particular, hot extremes, including HWs and TNs, have occurred more frequently and become more intense since the mid- $20^{\text {th }}$ century ${ }^{2-3,6-10}$. Society has paid much attention to those extreme heat events because they cause increases in mortality and morbidity, often because of cardiovascular disease $\mathrm{e}^{11-14}$.

The climate community has made a tremendous effort to understand the external and internal causes of extreme heat events and how they will change under global warming ${ }^{15-17}$. Most previous studies focused on detection and attribution of extreme heat events by comparing long-term changes in observations and climate model simulations from the Coupled Model Inter-comparison Project (CMIP) phase 3 or 5. Some studies have suggested that the increase in HWs could be attributed mainly to anthropogenic forcing, not natural variability ${ }^{2,4}$. However, other studies have suggested that natural climate variability, including the North Atlantic Oscillation, El Niño-Southern Oscillation (ENSO), monsoon, and Arctic Oscillation, is responsible for the occurrence of $\mathrm{HWs}^{18,19}$. Even though TNs cause more human deaths than $\mathrm{HWs}^{20}$, however, less attention has been paid to the role of anthropogenic forcing and natural variability in driving the increase in $\mathrm{TN}$ events. Furthermore, few attempts have been made to 
understand the different space-time response patterns and physical processes associated with HWs and TNs. In this study, we examine the statistics of HWs and TNs that occurred in the Northern Hemisphere (NH) during boreal summer (June, July, August; JJA) from 1980-2018 by analyzing observational datasets and 18 CMIP5 climate models (Method sections and Supplementary Table 1) to determine whether the recent increase in HWs and TNs is primarily controlled by anthropogenic forcing, natural variability, or both. To facilitate our analyses, we define pure HWs and pure $\mathrm{TNs}^{21}$ (Methods and Table 1), instead of using typical definitions, to clarify the physical processes and statistics associated with them.

\section{Results}

Contrasting trends in the HW and TN events in the NH during boreal summer We first show the frequency of HW and TN events in the NH during June, July, August, and JJA from 1980-2018 (Fig. 1). Although the occurrence of both HWs and TNs increased throughout the entire period (Supplementary Table 2a), both in each month and in JJA overall, the details of their temporal properties are quite different. The occurrence of HWs has increased gradually since 1980 (Figs. 1a-d), whereas TNs increased suddenly in the late 1990s, with negligible trends before and after that change (Supplementary Table 2b). In fact, the occurrence of TNs underwent a regime shift increase in the late 1990s (Supplementary Fig. 1 and Methods). A regime shift is characterized by an abrupt transition from one quasi-steady climate state (15-20 years) to another, with a transition period that is much shorter than the length of the individual epochs $^{22}$. No such abrupt increase was observed in HWs (Supplementary Fig. 1); they instead showed significant, consistent increases before and after the late 1990s for each month and JJA overall (Supplementary Table 2c). Furthermore, the simultaneous correlation coefficient in HW and TN frequency during JJA (Fig. 1d and Fig. 1h) is negligible, 0.04 for 1980-2018 without a linear trend, indicating that the variability in HWs and TNs is unrelated. In fact, HW 
occurrence is dominant on the interannual timescales without a linear trend, whereas a lowfrequency variability of TN occurrence is prominent (Supplementary Fig. 2). The differences in the temporal properties of HWs and TNs could indicate that the causes of their recent increases are not the same.

The significant increasing trend in HW occurrence for the entire period suggests that a primary influence is anthropogenic forcing, as indicated in previous studies ${ }^{2,4}$. We discuss this later in our analysis of the CMIP5 climate models. Most previous studies showed that anthropogenic forcing is the primary contributor to the gradual increase in HWs at the regional and global scales ${ }^{23,24}$. They argued that the number of global HW days increases as the global mean surface temperature increases ${ }^{25,26}$. Furthermore, they predict that future HW events in most regions in the $\mathrm{NH}$ will become more intense, more frequent, and longer lasting in the second half of the $21^{\text {st }}$ century ${ }^{5}$. Although a regression analysis does not imply causality, regressed sea surface temperature (SST) anomalies against the frequency of HWs supports the notion that the increasing trend in HW events is associated with an increase in global SST, in addition to an increase in land surface temperature (Supplementary Fig. 3). Furthermore, the variability in HW events (without a linear trend) is closely associated with an El Nino-like SST structure $^{27,28}$ (Supplementary. Fig. 4). This suggests that the increasing trend in HWs in the NH during JJA is mostly due to anthropogenic global warming and the remaining interannual variability in HW occurrence is affected by natural variability, including ENSO.

In contrast, the significant increasing trend in $\mathrm{TN}$ occurrence across the entire period is characterized by a regime shift-like increase in the late 1990s (Figs. 1e-h and Supplementary Fig. 1). In other words, the increase in TNs after the late 1990s cannot be explained solely by anthropogenic forcing. 
frequency before and after the regime shift (1998-2018 minus 1980-1997). The distinct increase in TN occurrence is significant over several regions: Western Europe, East Asia, Northeastern Eurasia, central Africa, and southwestern North America. To examine the cause of that abrupt increase in TN events, we calculate the regressed SST anomalies against the time series of TN occurrences with and without a linear trend (Figs. 2b,c). Both SST anomalies are characterized by warm temperatures in a horseshoe shape in the western-to-central North and South Pacific accompanied by anomalously cool temperatures in the tropical eastern Pacific Ocean, which is similar to the conditions during a negative phase of the Pacific Decadal Oscillation (PDO) (see also Supplementary Fig. 5). Furthermore, a positive phase of the Atlantic Multi-decadal Oscillation-like SST is also evident along with warm SST in the Indian Ocean basin (Figs. 2b,c). Note that without a linear trend, the TN occurrence during JJA is also characterized by a regime shift increase during the late 1990s although its amplitude is weaker (Fig. 2d,e). This result indicates that the regime shift-like increase in TN occurrence is largely explained by natural climate variability associated with low-frequency SST variations, including the PDO.

Human and natural causes of the contrasting trends between HWs and TNs. To examine those hypotheses, we analyze the frequency of HWs and TNs simulated by 18 CMIP5 climate models, using their ensemble means for each summer month and JJA during 1980-2018 (Fig. 3). In this analysis, we combined historical simulations for 1980-2005 with the corresponding Representative Concentration Pathway (RCP) 4.5 scenario simulations for 2006-2018 (see also Methods). In the multi-model ensemble means and in each ensemble member, HWs show statistically significant increasing trends during June, July, August, and JJA overall, although the magnitude of the trend was weaker than in the observations (Figs. 3a-d). Statistically significant increases in the occurrence of HWs are also found in all the individual models 
(figure not shown). Unlike in the observations, however, the ensemble means for July, August, and JJA present a regime shift increase in the occurrence of HWs in the late 1990s (Supplementary Fig. 6), mostly due to a large increase in HW occurrences after the late 1990s (Supplementary Table 3) that can be explained by stronger anthropogenic forcing during recent decades. It is noteworthy that the increasing trend in HW events after the late 1990s is also larger than that before the late 1990s in the observations (Supplementary Table 2). Thus, this supports that anthropogenic forcing significantly contributes to the increase in observed HWs in the recent past.

On the other hand, in contrast to the observations (Figs. 1e-h), the multi-model ensemble means for TN events show statistically significant increasing trends during June, July, August, and JJA overall (Figs. 3e-h). Those statistically significant increases in TN occurrence are also found in each individual model (figure not shown). Although the ensemble mean for TN events also experienced a regime shift increase after the late 1990s (Supplementary Fig. 6), in accordance with the observations, its increasing trend after the late 1990s remains significant, unlike the observations (Supplementary Table 3). We argue that increases in both HW and TN events after the late 1990s could be caused by anthropogenic forcing in CMIP5 climate models. Furthermore, we find coherence in the HW and TN occurrences simulated in the CMIP5 climate models regardless of a linear trend, which is in contrast to the observations. Whereas the variabilities in HW and TN events are poorly correlated without linear trends in the observations, they are highly correlated in each CMIP5 climate model, with and without linear trends (Supplementary Table 4). Furthermore, the simultaneous correlation coefficient between the ensemble mean for the occurrence of HW and TN events in JJA is 0.99 and 0.88 with and without linear trends, respectively, which are statistically significant above the $99 \%$ confidence level. These results indicate that although anthropogenic forcing plays a major role in the increase in TNs in the CMIP5 climate models, as with the occurrence of HWs, natural 
variability largely explains the regime shift-like temporal structure of TN occurrences in the observations.

We further examine the physical processes associated with the TNs simulated in each CMIP5 climate model. To do so, we calculate the regressed SST anomalies against TN occurrence without a linear trend in each model (Figs. 4a-r). Unlike the observations, the regressed SST anomalies in most CMIP5 climate models are characterized by an El Nino-like SST structure or a positive phase of PDO-like SST. The ensemble mean structure (Fig. 4s) is characterized by warm SST in the central-to-eastern tropical Pacific and the Indian Ocean basin, with cool SST anomalies in the western-to-central North Pacific. It should be noted that the ensemble mean structure of regressed SST against with the HW frequency without a linear trend in CMIP5 climate models are similar to each other (Supplementary Fig. 7). These results suggest that the variability in the occurrence of both HWs and TNs is associated with a similar SST structure in the CMIP5 climate models.

\section{Discussion}

We conclude that the contributing factors associated with variability in the occurrence of HWs and TNs are similar in the CMIP5 climate models, which is not seen in the observation. While the increasing trend in HWs in the NH during JJA is mostly due to anthropogenic global warming, the significant increasing trend in $\mathrm{TN}$ occurrence across the entire period is characterized by a regime shift-like increase in the late 1990s. Therefore, the increase in TNs in the observation cannot be explained solely by anthropogenic forcing. In particular, we emphasize that the CMIP5 climate models fail to simulate the characteristics of TN occurrence found in the observations, which could be caused by the models' failure to correctly simulate decadal SST variability in the tropics ${ }^{29}$. This implies that the uncertainty in future projections based on the CMIP5 climate models can be large for extreme heat events, particularly TNs, 
which should be carefully considered.

\section{Methods}

Observational datasets In this study, we used two observational gridded datasets, the Climate Prediction Center (CPC) global daily temperature ${ }^{30}$ and the Hadley Centre Sea Ice and Sea Surface Temperature ${ }^{31}$ (HadISST). The CPC daily temperature dataset, with a horizontal resolution of $0.5^{\circ} \times 0.5^{\circ}$, was developed by the American National Oceanic and Atmospheric Administration (NOAA) using the Shepard algorithm and Global Telecommunication System data. The data provided are the maximum temperature $\left(T_{\max }\right)$ and minimum temperature $\left(T_{\min }\right)$; we calculated the average daily temperature $\left(T_{\text {mean }}\right)$ from $T_{\max }$ and $T_{\min }$. Monthly SST data were obtained from HadISST. The period is boreal summer from 1980 to 2018.

CMIP5 climate models CMIP5 historical simulations for the period of 1980 to 2005 and RCP4.5 simulations from 2006 to 2018 were used. Historical runs were simulated using the time-varying observed atmospheric composition as affected by both anthropogenic and volcanic influences, solar forcing, emissions or concentrations of short-lived species, natural and anthropogenic aerosols or their precursors, and land use. The RCP4.5 runs assumed that radiative forcing will increase and then stabilize at approximately $4.5 \mathrm{~W} / \mathrm{m}^{2}$ after $2100^{32}$.

Heatwave (HW) and Tropical Night (TN) events We used a percentile threshold to statistically approach pure HWs and TNs in the NH during boreal summer (June-to-August). The climatology was for the period of June, July, and August from 1981 to 2010. Pure HW events were calculated as days when $T_{\max }$ equaled or exceeded the $90^{\text {th }}$ percentile of the climatological $T_{\max }$, and $T_{\min }$ was inferior to the $90^{\text {th }}$ percentile of the climatological $T_{\min }$ on each grid. Pure TN events were calculated as days when $T_{\min }$ equaled or exceeded the $90^{\text {th }}$ 
percentile of climatological $T_{\min }$, and $T_{\max }$ was inferior to the $90^{\text {th }}$ percentile of climatological $T_{\max }$ on each grid. We identically applied a percentile threshold to define pure HWs and TNs simulated in CMIP5 climate models like the observation. For June, July, and August from 1980 to 2005, we used CMIP5 historical simulation data, and for June, July, and August from 2006 to 2010, we combined CMIP5 RCP4.5 simulation data. The climatology data were from 1981 to 2010 in each CMIP5 climate model.

Regime shift analysis and Power spectral analysis The regime shift analysis used a method developed by Rodionov ${ }^{33}$ on the basis of a two-tailed student's test (details of regime shift detection are offered by NOAA, available at http://www.beringclimate.noaa.gov/regimes/\#userconsent\#). This method was applied to the time series of HW and TN occurrences. Before the regime shift analysis, we set the significance level to 0.05 , cut-off length to 15 , and Huber weight parameter to 1 . If there were not 15 years left before and after a regime shift year, it is not shown in the regime shift index. The confidence level for the difference between the mean values of neighboring regimes was more than $99 \%$. We also conducted the power spectral analysis using the NCL https://www.ncl.ucar.edu/Document/Functions/Shea_util/specx_ci.shtml

\section{Code availability}

All other code used to produce the figures can be made available upon request from the corresponding author.

\section{Data availability}

All model output analysed in the study is stored on the data servers at the Hanyang Unviersity in Ansan, South Korea, and can be made available upon request from the corresponding author. 
The observational datasets that support the findings are publicly available. The CPC daily temperature dataset provided by the NOAA/OAR/ESRL PSD, Boulder, Colorado, USA, from their website at https://psl.noaa.gov/data/gridded/data.cpc.globaltemp.html. The HadISST data could be accessed via https://psl.noaa.gov/data/gridded/data.cpc.globaltemp.html.

\section{References}

1 Arguez, A. et al. Should we expect each year in the next decade (2019-2028) to be ranked among the top 10 warmest years globally? Bulletin of the American Meteorological Society (2020).

2 Wang, J. et al. Anthropogenically-driven increases in the risks of summertime compound hot extremes. Nature communications 11, 1-11 (2020).

3 Perkins, S., Alexander, L. \& Nairn, J. Increasing frequency, intensity and duration of observed global heatwaves and warm spells. Geophysical Research Letters 39 (2012).

4 Coumou, D. \& Rahmstorf, S. A decade of weather extremes. Nature climate change 2 , 491-496 (2012).

5 Meehl, G. A. \& Tebaldi, C. More intense, more frequent, and longer lasting heat waves in the 21st century. Science 305, 994-997 (2004).

6 Seneviratne, S. I. et al. Changes in climate extremes and their impacts on the natural physical environment.: Managing the Risks of Extreme Events and Disasters to Advance Climate Change Adaptation (SREX) Chapter: 3Publisher: Cambridge University Press, Cambridge, UK, and New York, NY, USAEditors: Field, V. Barros, T.F. Stocker, D. Qin, D.J. Dokken, K.L. Ebi, M.D. Mastrandrea, K.J. Mach, G.-K. Plattner, S.K. Allen, M. Tignor, P.M. Midgley (2017).

7 Kim, Y.-H. et al. Attribution of extreme temperature changes during 1951-2010. Climate dynamics 46, 1769-1782 (2016). 
2498 Chen, R. \& Lu, R. Dry tropical nights and wet extreme heat in Beijing: Atypical 250 configurations between high temperature and humidity. Monthly Weather Review 142, 1792$251 \quad 1802(2014)$.

2529 Bindoff, N. L. et al. Detection and attribution of climate change: from global to 253 regional. (2013).

$254 \quad 10 \mathrm{Su}, \mathrm{Q}$. \& Dong, B. Recent decadal changes in heat waves over China: drivers and 255 mechanisms. Journal of Climate 32, 4215-4234 (2019).

25611 Mora, C. et al. Global risk of deadly heat. Nature Climate Change 7, 501-506 (2017).

25712 Lesk, C., Rowhani, P. \& Ramankutty, N. Influence of extreme weather disasters on 258 global crop production. Nature 529, 84-87 (2016).

25913 Hadley, S. W., Erickson, D. J., Hernandez, J. L., Broniak, C. T. \& Blasing, T. 260 Responses of energy use to climate change: A climate modeling study. Geophysical research $261 \quad$ letters 33 (2006).

26214 McMichael, A. J., Woodruff, R. E. \& Hales, S. Climate change and human health: 263 present and future risks. The Lancet 367, 859-869 (2006).

26415 Fischer, E. M., Seneviratne, S. I., Vidale, P. L., Lüthi, D. \& Schär, C. Soil moisture265 atmosphere interactions during the 2003 European summer heat wave. Journal of Climate 20, 5081-5099 (2007).

$267 \quad 16 \quad$ Francis, J. A. \& Vavrus, S. J. Evidence linking Arctic amplification to extreme weather 268 in mid-latitudes. Geophysical research letters 39 (2012).

26917 Lee, W. S. \& Lee, M. I. Interannual variability of heat waves in South Korea and their connection with large-scale atmospheric circulation patterns. International Journal of Climatology 36, 4815-4830 (2016). 18 Fang, X., Wang, A., Fong, S.-k., Lin, W. \& Liu, J. Changes of reanalysis-derived 273 Northern Hemisphere summer warm extreme indices during 1948-2006 and links with 
climate variability. Global and Planetary Change 63, 67-78 (2008).

19 Liu, Q., Zhou, T., Mao, H. \& Fu, C. Decadal Variations in the Relationship between the Western Pacific Subtropical High and Summer Heat Waves in East China. Journal of Climate 32, 1627-1640 (2019).

20 Fischer, E. M. \& Schär, C. Consistent geographical patterns of changes in high-impact European heatwaves. Nature Geoscience 3, 398-403 (2010).

21 Hong, J. S., Yeh, S. W. \& Seo, K. H. Diagnosing physical mechanisms leading to pure heat waves versus pure tropical nights over the Korean Peninsula. Journal of Geophysical Research: Atmospheres 123, 7149-7160 (2018).

22 Hong, C.-C. \& Wu, Y.-K. Influence of Climate Regime Shift on the Abrupt Change of Tropical Cyclone Activity in Various Genesis Regions. Extreme Weather, 11 (2018). 23 Russo, S., Sillmann, J. \& Sterl, A. Humid heat waves at different warming levels. Scientific reports 7, 1-7 (2017).

24 Fischer, E. M. \& Knutti, R. Anthropogenic contribution to global occurrence of heavyprecipitation and high-temperature extremes. Nature Climate Change 5, 560-564 (2015). 25 Collins, D., Della-Marta, P., Plummer, N. \& Trewin, B. Trends in annual frequencies of extreme temperature events in Australia. Australian Meteorological Magazine 49, 277-292 (2000).

26 Peterson, T. C., Zhang, X., Brunet-India, M. \& Vázquez-Aguirre, J. L. Changes in North American extremes derived from daily weather data. Journal of Geophysical Research: Atmospheres 113 (2008).

27 Luo, M. \& Lau, N.-C. Amplifying effect of ENSO on heat waves in China. Climate dynamics 52, 3277-3289 (2019).

28 Coumou, D., Robinson, A. \& Rahmstorf, S. Global increase in record-breaking monthly-mean temperatures. Climatic Change 118, 771-782 (2013). 
300 Indian summer monsoon in CMIP5 models. Climate Dynamics 51, 3023-3039 (2018).

30130 Climate Prediction Center. CPC Global Daily Temperature Analysis.

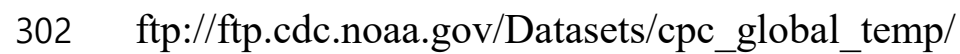

30331 Rayner, N. A. Global analyses of sea surface temperature, sea ice, and night marine air 304 temperature since the late nineteenth century. Journal of Geophysical Research 108, 305 doi:10.1029/2002jd002670 (2003).

30632 Taylor, K. E., Stouffer, R. J. \& Meehl, G. A. An Overview of CMIP5 and the 307 Experiment Design. Bulletin of the American Meteorological Society 93, 485-498, 308 doi:10.1175/bams-d-11-00094.1 (2012).

30933 Rodionov, S. N. A sequential algorithm for testing climate regime shifts. Geophysical 310 Research Letters 31 (2004). 
312 Table 1. Definitions of pure heat waves (HWs) and tropical nights (TNs).

\begin{tabular}{lll}
\hline & \multicolumn{1}{c}{ HWs } & \multicolumn{1}{c}{ TNs } \\
\hline & $T_{\max } \geq 90^{\text {th }}$ percentile & $T_{\min } \geq 90^{\text {th }}$ percentile \\
threshold of & threshold of \\
& climatological $T_{\max }$ and & climatological $T_{\min }$ and \\
Definition & $T_{\min }<90^{\text {th }}$ percentile & $T_{\max }<90^{\text {th }}$ percentile \\
& threshold of & threshold of \\
& climatological $T_{\min }$ & climatological $T_{\max }$ \\
\hline
\end{tabular}



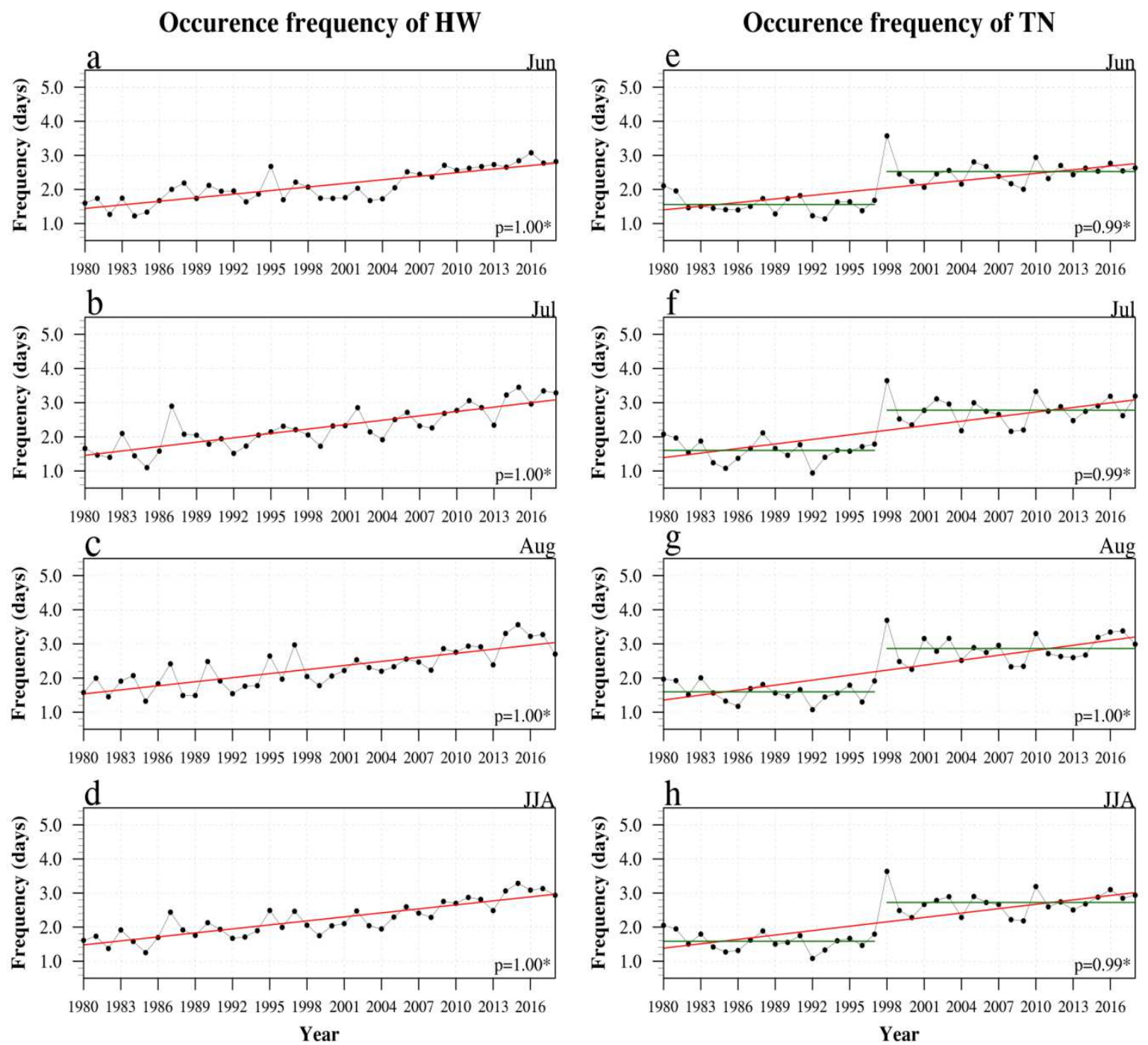

315 Fig. 1. Observational time series of HW and TN occurrences. The frequency of HWs and

316 TNs was calculated using the daily and area-weighted average in the Northern Hemisphere 317 from 1980 to 2018. a Frequency of HWs in June. b, c, and d Same as a, but in July, August, 318 and JJA, respectively. e Frequency of TNs in June. f, g, and h Same as e, but in July, August, 319 and JJA, respectively. The red line indicates a linear trend. The value in the bottom right of 320 each figure indicates the significance probability of a linear trend. The green line denotes the mean value of the regime. 


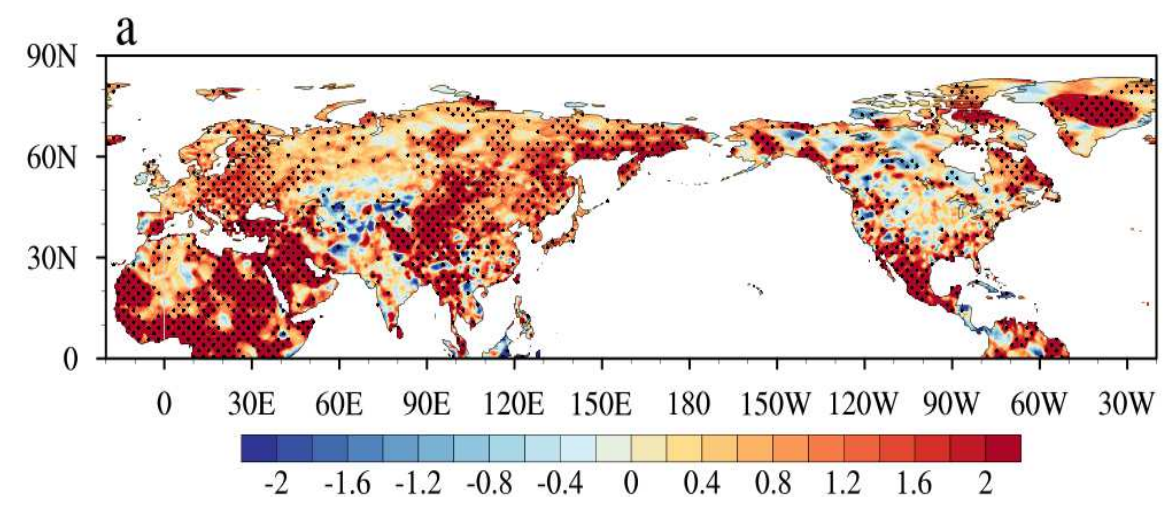

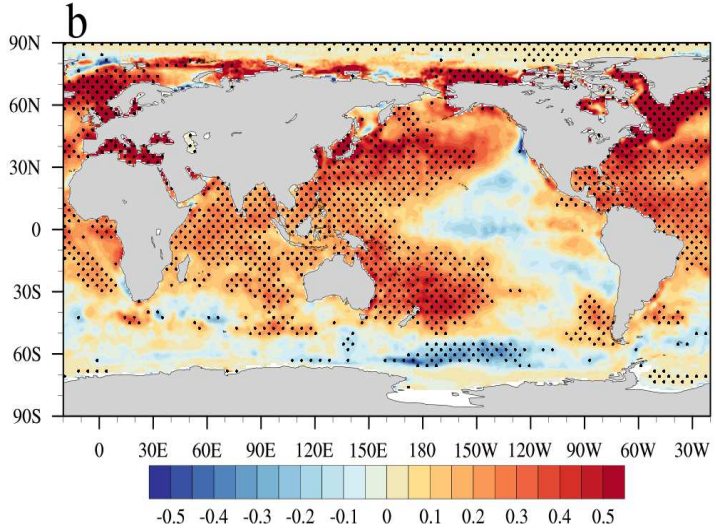

Occurence frequency of TN

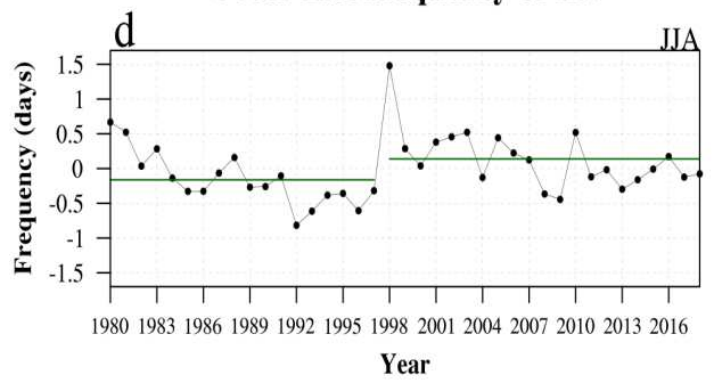

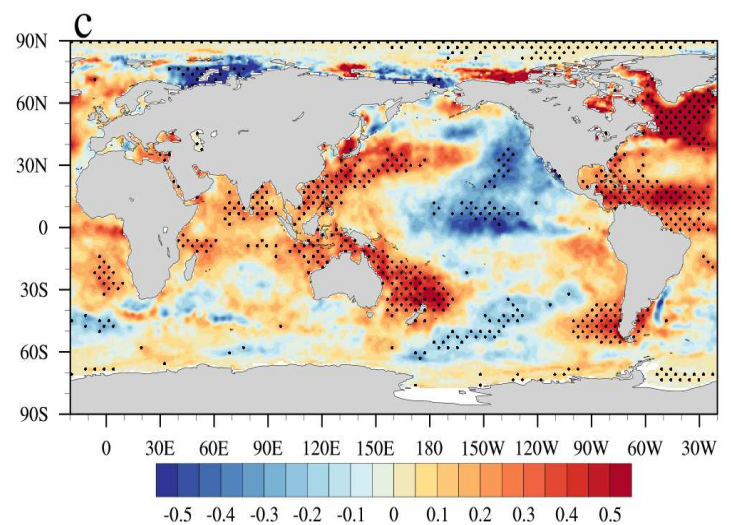

Regime shift index

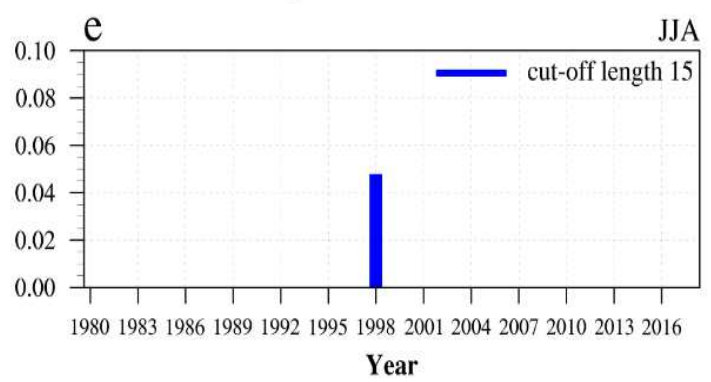

323 Fig. 2. The characteristic properties in TN occurrence frequency. a Differences in TN

324 frequency in the Northern Hemisphere before and after the regime shift. The differences were calculated by subtracting the mean $\mathrm{TN}$ frequency before the regime from the mean $\mathrm{TN}$ frequency after the regime. The unit is day/month. $\mathbf{b}, \mathbf{c}$ indicate the regressed of SST anomalies against the time series of TN occurrences with and without a linear trend, respectively. SST anomalies were calculated by subtracting the climatology (1980-2018) from the raw SST dataset. Unit in $\mathbf{b}, \mathbf{c}$ is ${ }^{\circ} \mathrm{C}$. The black dots denote areas significant at the $95 \%$ confidence level. d observational time series of TN occurrences without a linear trend. e Regime shift index of $\mathrm{TN}$ frequency without a linear trend. In analyzing the regime shift, the following parameters were used: probability level of 0.05 , cut-off length set to 15 , and Huber's weight parameter of 1.0. The confidence level of the difference between the mean values of the neighboring regimes is above $99 \%$. 

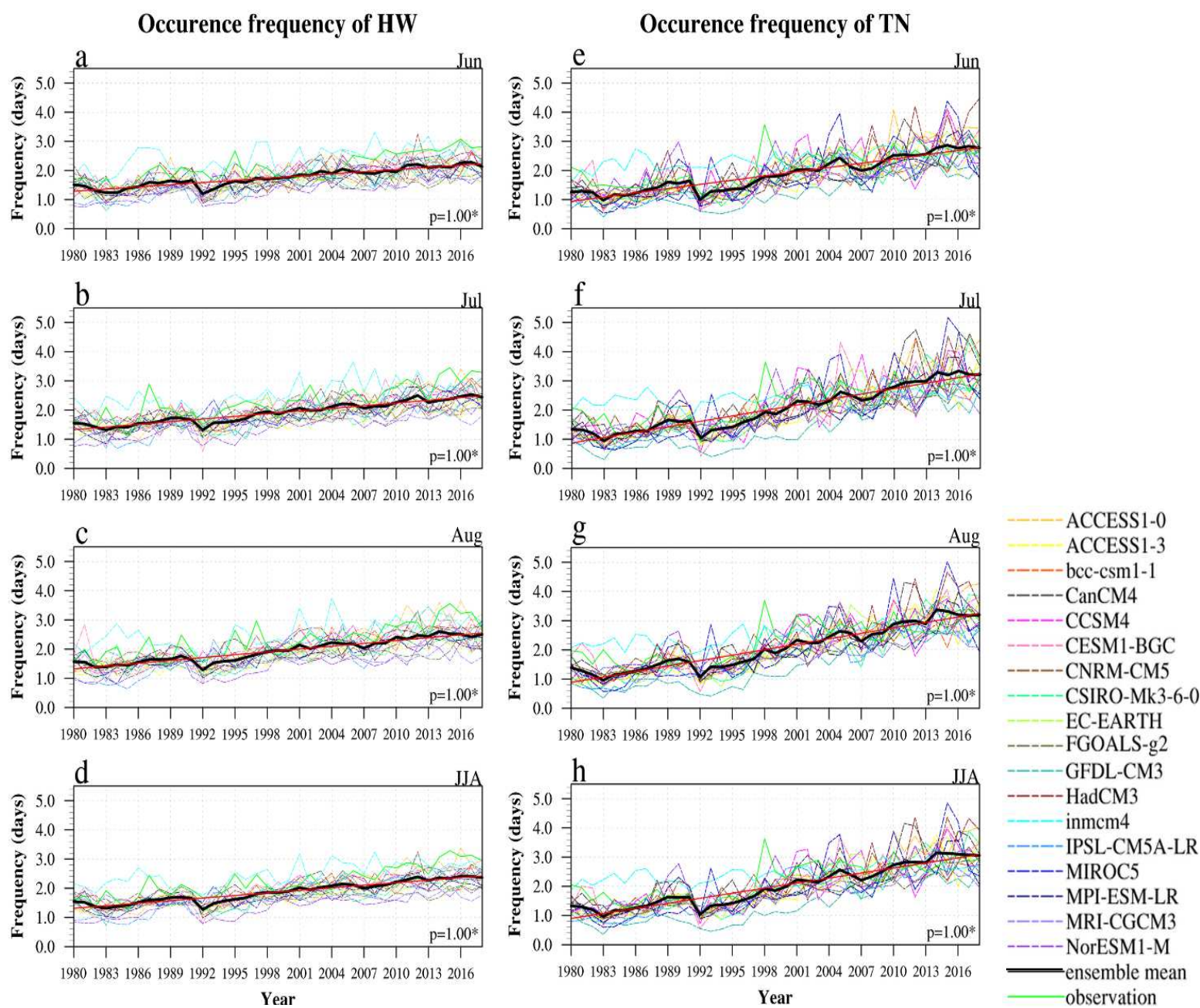

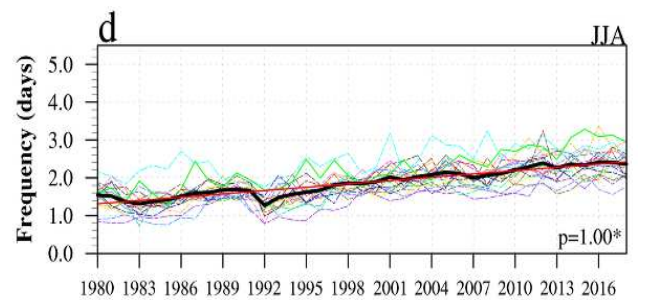

Year

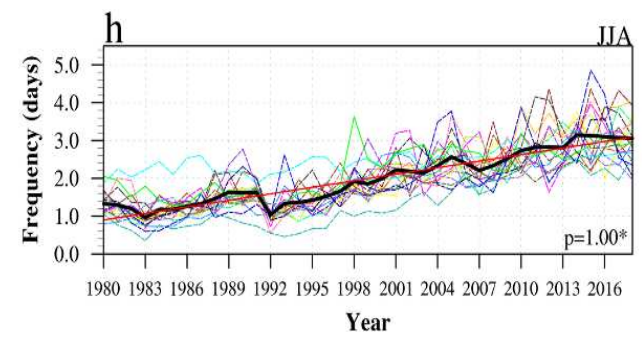

336 Fig. 3. Time series of HW and TN occurrences in CMIP5 models. The frequency of HWs and TNs was calculated using daily and area-weighted averages in the Northern Hemisphere from 1980 to 2018. a Frequency of HWs in June. b, c, and d Same as a, but in July, August, and JJA, respectively. e Frequency of TNs in June. f, $\mathbf{g}$, and $\mathbf{h}$ Same as e, but in July, August, and JJA, respectively. The black line shows the ensemble mean of 18 CMIP5 models. The red line indicates a linear trend of the ensemble mean. The value in the bottom right of each figure denotes the significance probability of a linear trend. The legends on the bottom right represent the individual models, ensemble mean, and observation data. 

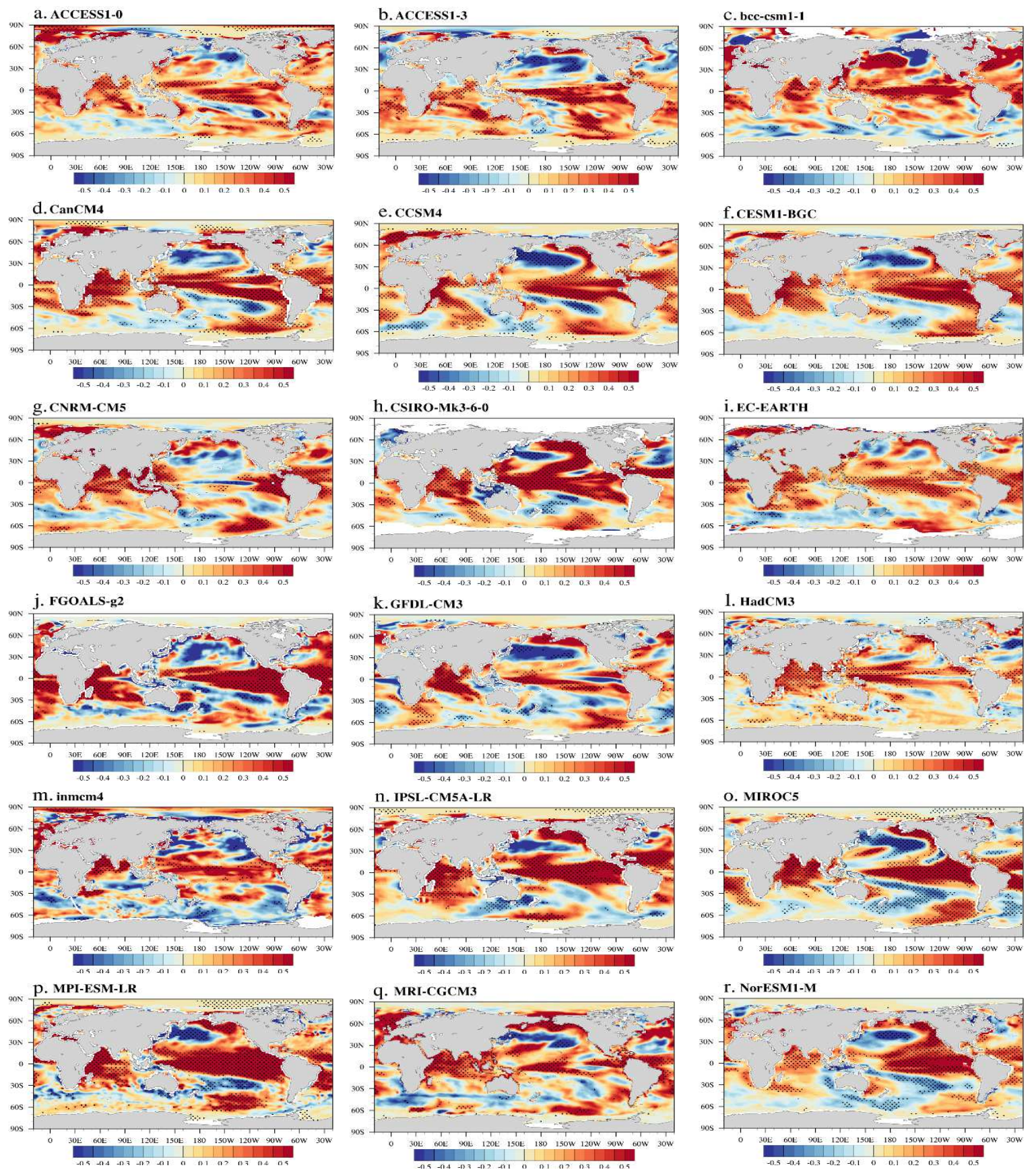

S. ensemble mean

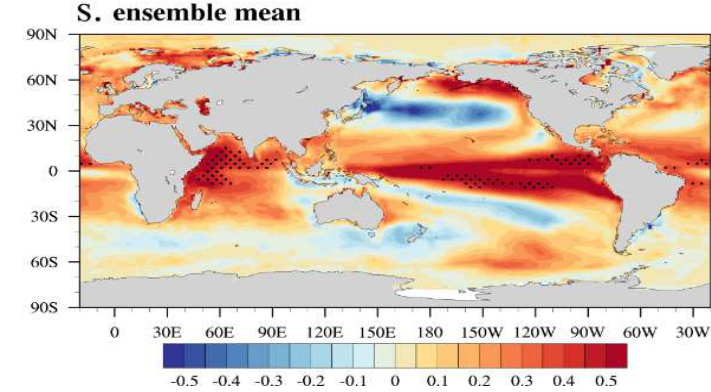

345 Fig. 4. Regression of SST anomalies against TN frequency without a linear trend in 18

346 CMIP5 climate models. a The regression of SST anomalies against the time series of TN 347 occurrences in JJA without a linear trend in the ACCESS1-0 model. $\mathbf{b}, \mathbf{c}, \mathbf{d}, \mathbf{e}, \mathbf{f}, \mathbf{g}, \mathbf{h}, \mathbf{i}, \mathbf{j}, \mathbf{k}, \mathbf{l}$, 
$348 \mathbf{m}, \mathbf{n}, \mathbf{o}, \mathbf{p}, \mathbf{q}, \mathbf{r}, \mathbf{s}$ Same as a, but for ACCESS 1-3, bcc-csm1-1, CanCM4, CCSM4, CESM1349 BGC, CNRM-CM5, CSIRO-Mk3-6-0, EC-EARTH, FGOALS-g2, GFDL-CM3, HadCM3, 350 inmcm4, IPSL-CM5A-LR, MIROC5, MPI-ESM-LR, MRI-CGCM3, NorESM1-M, and 351 ensemble mean, respectively. SST anomalies were calculated using climatology across the 352 entire period in each individual model. The unit is ${ }^{\circ} \mathrm{C}$. The black dots indicate areas significant 353 at the $95 \%$ confidence level. 
Supplementary Table 1. Description of the CMIP5 climate models used in this paper.

\begin{tabular}{cccc}
\hline \hline Model & Institution ID / Country & $\begin{array}{c}\text { Resolution (Lon. x Lat.) } \\
\text { Ocean/atmosphere }\end{array}$ \\
\hline $\mathbf{1}$ & ACCESS1-0 & CSIRO-BOM / Australia & $360 \times 181 / 192 \times 145$ \\
\hline $\mathbf{2}$ & ACCESS1-3 & CSIRO-BOM / Australia & $360 \times 181 / 192 \times 145$ \\
\hline $\mathbf{3}$ & bcc-csm1-1 & BCC / China & $360 \times 181 / 128 \times 64$ \\
\hline $\mathbf{4}$ & CanCM4 & CCCma / Canada & $360 \times 181 / 128 \times 64$ \\
\hline $\mathbf{5}$ & CCSM4 & NCAR / USA & $360 \times 181 / 288 \times 192$ \\
\hline $\mathbf{6}$ & CESM1-BGC & NSF-DOE-NCAR / USA & $360 \times 181 / 288 \times 192$ \\
\hline $\mathbf{7}$ & CNRM-CM5 & CNRM-CERFACS / France & $360 \times 181 / 256 \times 128$ \\
\hline $\mathbf{8}$ & CSIRO-Mk3-6-0 & CSIRO-QCCCE / Australia & $360 \times 181 / 192 \times 96$ \\
\hline $\mathbf{9}$ & EC-EARTH & EC-EARTH / Europe & $360 \times 181 / 320 \times 160$ \\
\hline $\mathbf{1 0}$ & FGOALS-g2 & LASG-CESS / China & $360 \times 181 / 128 \times 60$ \\
\hline $\mathbf{1 1}$ & GFDL-CM3 & NOAA-GFDL / USA & $360 \times 181 / 144 \times 90$ \\
\hline $\mathbf{1 2}$ & HadCM3 & MOHC / UK & $360 \times 181 / 96 \times 73$ \\
\hline $\mathbf{1 3}$ & inmcm4 & INM / Russia & $360 \times 181 / 180 \times 120$ \\
\hline $\mathbf{1 4}$ & IPSL-CM5A-LR & IPSL / France & $360 \times 181 / 96 \times 96$ \\
\hline $\mathbf{1 5}$ & MIROC5 & MIROC / Japan & $360 \times 181 / 256 \times 128$ \\
\hline $\mathbf{1 6}$ & MPI-ESM-LR & MPI-M / Germany & $360 \times 181 / 192 \times 96$ \\
\hline $\mathbf{1 7}$ & MRI-CGCM3 & MRI / Japan & $360 \times 181 / 320 \times 160$ \\
\hline $\mathbf{1 8}$ & NorESM1-M & NCC / Norway & $360 \times 181 / 144 \times 96$ \\
\hline & & &
\end{tabular}


356 Supplementary Table 2. Linear trends in HW and TN frequency in observational data. a

357 Linear trends in HW and TN frequency for the entire period (1980-2018). b Linear trends in

358 TN frequency in each month before and after the late 1990s. c Same as b, but for HWs. The 359 unit is number of events/year. Statistical significance at the $90 \%, 95 \%$, and $99 \%$ level is 360 denoted by *,**, and ***, respectively.

\begin{tabular}{lcc}
\hline \hline & $\begin{array}{c}\text { a. } \\
\text { Trends of HW and TN occurrence frequency } \\
\text { for the entire period (1980-2018) }\end{array}$ \\
\hline Jun & HW & TN \\
\hline Jul & $0.04 * * *$ & $0.04 * * *$ \\
\hline Aug & $0.04 * * *$ & $0.04 * * *$ \\
\hline JJA & $0.04 * * *$ & $0.05 * * *$ \\
\hline \hline
\end{tabular}

b. Trends of TN occurrence frequency before and after the late 1990s

\begin{tabular}{ccc}
\hline & $1980-1997$ & $1998-2018$ \\
\hline Jun & -0.01 & 0.00 \\
\hline Jul & -0.01 & 0.00 \\
\hline Aug & -0.01 & 0.01 \\
\hline JJA & -0.01 & 0.00 \\
\hline \hline
\end{tabular}

c. Trend of HW occurrence frequency before and after the late 1990s

\begin{tabular}{ccc}
\hline & $1980-1997$ & $1998-2018$ \\
\hline Jun & $0.04^{* * *}$ & $0.06^{* * *}$ \\
\hline Jul & $0.04^{*}$ & $0.06^{* * *}$ \\
\hline Aug & $0.04^{*}$ & $0.06^{* * *}$ \\
\hline JJA & $0.04^{* *}$ & $0.06^{* * *}$ \\
\hline
\end{tabular}


Supplementary Table 3. Linear trends in HW and TN occurrence frequency in CMIP5.

a Linear trends of HW occurrence frequency before and after the late 1990s each month. b

364 Same as a, but for TN. The unit is occurrence frequency number/year. The statistical

365 significance at the $99 \%$ level was shown by *.

\begin{tabular}{ccc}
\hline \hline \multicolumn{3}{c}{ a. Trend of HW occurrence frequency before and after the late 1990s } \\
\hline & Before the late 1990s & After the late 1990s \\
\hline Jun & 0.01 & $0.03^{*}$ \\
\hline Jul & 0.01 & $0.03^{*}$ \\
\hline Aug & 0.01 & $0.03^{*}$ \\
\hline JJA & 0.01 & $0.03^{*}$ \\
\hline \hline
\end{tabular}

\begin{tabular}{ccc}
\hline \hline \multicolumn{3}{c}{ b. Trend of TN occurrence frequency before and after the late 1990s } \\
\hline & Before the late 1990s & After the late 1990s \\
\hline Jun & 0.01 & $0.06^{*}$ \\
\hline Jul & 0.02 & $0.08^{*}$ \\
\hline Aug & 0.02 & $0.07^{*}$ \\
\hline JJA & 0.02 & $0.07^{*}$ \\
\hline
\end{tabular}


367 Supplementary Table 4. Correlation coefficients between HW and TN frequency in 368 CMIP5 18 models with and without a linear trend. Statistical significance at the 95\% and $36999 \%$ level is denoted by $*$ and $* *$, respectively.

\begin{tabular}{ccc}
\hline \multicolumn{2}{c}{ Correlation coefficient between HW and TN occurrence frequency in JJA (CMIP5) } \\
\hline & with (a linear) trend & without (a linear) trend \\
\hline ACCESS1-0 & $0.94^{* *}$ & $0.62^{* *}$ \\
\hline ACCESS1-3 & $0.91^{* *}$ & $0.58^{* *}$ \\
\hline bcc-csm1-1 & $0.89^{* *}$ & $0.64^{* *}$ \\
\hline CanCM4 & $0.89^{* *}$ & $0.65^{* *}$ \\
\hline CCSM4 & $0.89^{* *}$ & $0.66^{* *}$ \\
\hline CESM1-BGC & $0.92^{* *}$ & $0.76^{* *}$ \\
\hline CNRM-CM5 & $0.94^{* *}$ & $0.84^{* *}$ \\
\hline CSIRO-Mk3-6-0 & $0.91^{* *}$ & $0.81^{* *}$ \\
\hline EC-EARTH & $0.87^{* *}$ & $0.60^{* *}$ \\
\hline FGOALS-g2 & $0.86^{* *}$ & $0.51^{* *}$ \\
\hline GFDL-CM3 & $0.91^{* *}$ & $0.65^{* *}$ \\
\hline HadCM3 & $0.81^{* *}$ & $0.47^{* *}$ \\
\hline inmcm4 & $0.68^{* *}$ & $0.39^{*}$ \\
\hline IPSL-CM5A-LR & $0.95^{* *}$ & $0.74^{* *}$ \\
\hline MIROC5 & $0.85^{* *}$ & $0.61^{* *}$ \\
\hline MPI-ESM-LR & $0.88^{* *}$ & $0.70^{* *}$ \\
\hline MRI-CGCM3 & $0.72^{* *}$ & $0.49^{* *}$ \\
\hline NorESM1-M & $0.93^{* *}$ & $0.81^{* *}$ \\
\hline \hline
\end{tabular}




\section{Regime shift index}
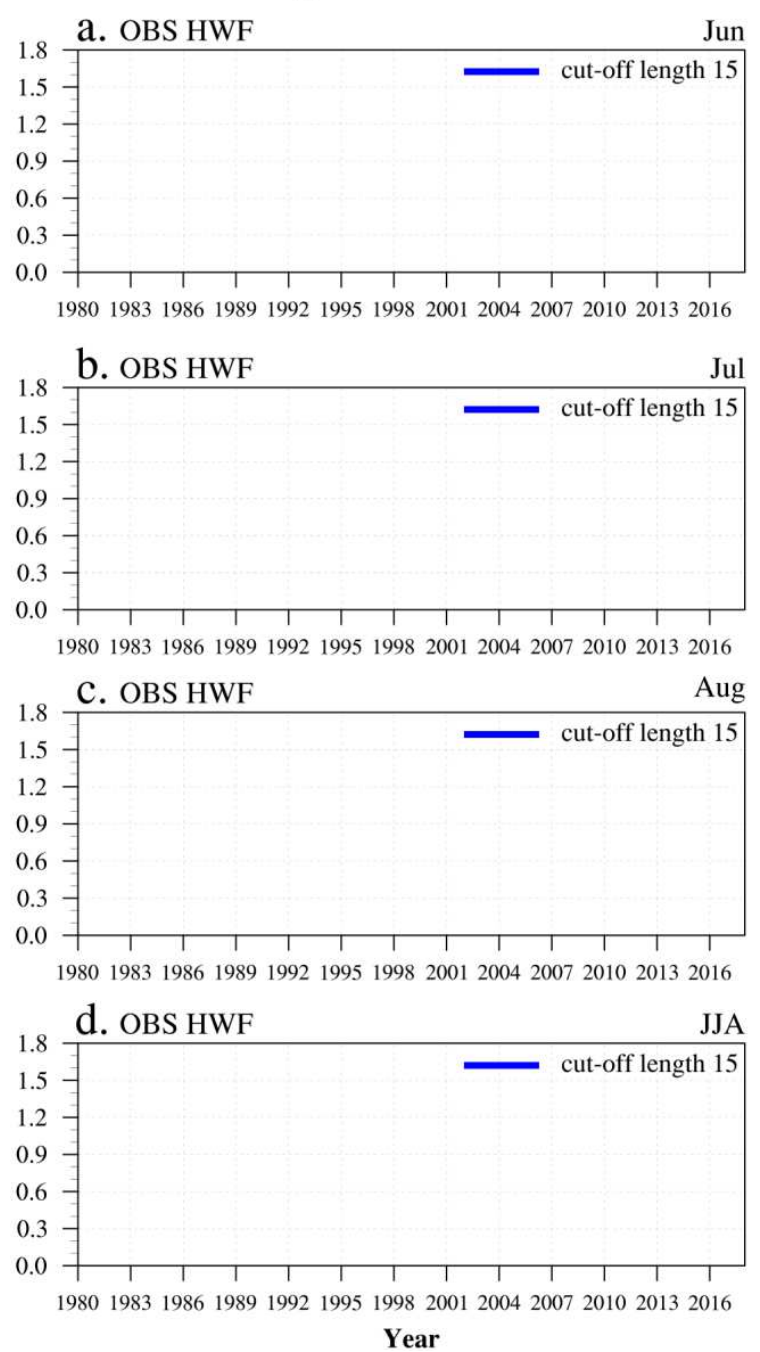

\section{Regime shift index}
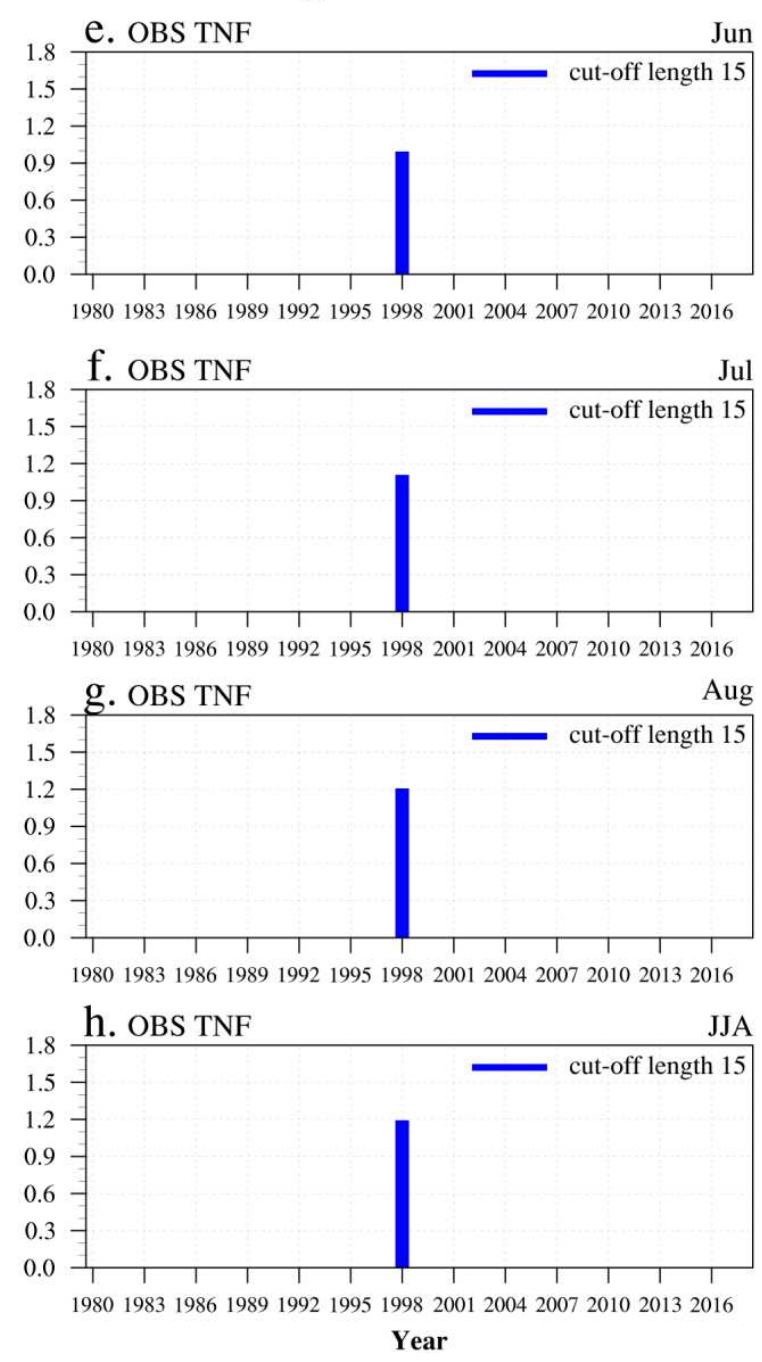

371 Supplementary Fig. 1 Regime shift detection in HW and TN frequency. a Regime shift index of HW frequency in June with observational data. b, c, d Same as a, but in July, August, and JJA, respectively. e-h are the same as in a-d except but the regime shift index of TN frequency with observational data. The blue bar represents the regime shift index identified with the regime shift analysis. In determining the regime shift index, the following parameters were used: probability level of 0.05 , cut-off length set at 15, and Huber's weight parameter of 1.0. The confidence level of the difference between the mean values of the neighboring regimes is above $99 \%$. 

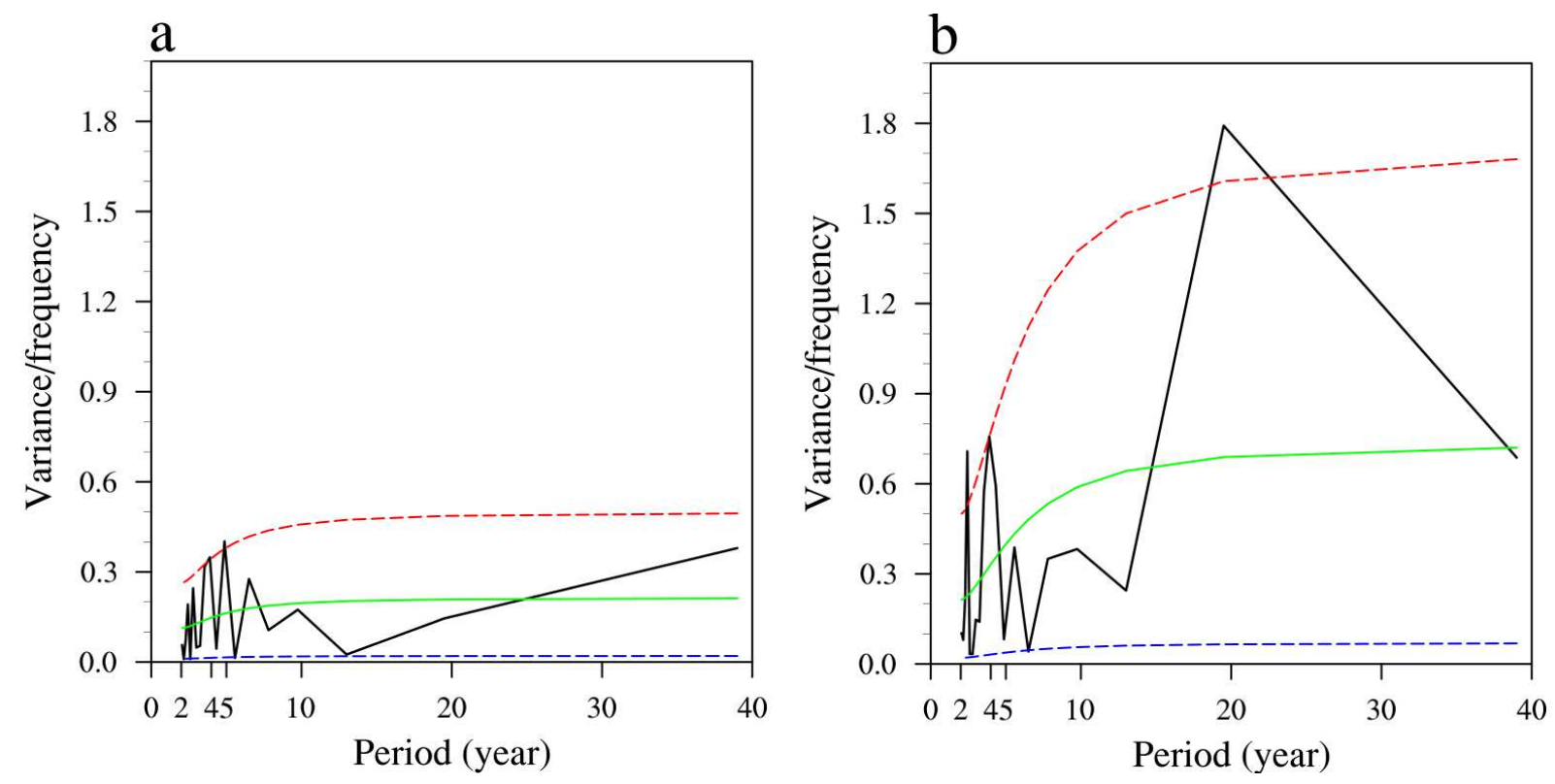

380 Supplementary Fig. 2 Power spectrum of HW (a) and TN (b) frequency without a linear

381 trend. The thick black lines indicate the power spectrum for HW and TN frequency in JJA

382 without a linear trend. As an indicator, the dashed blue and red lines show the lower $10 \%$ and 383 upper $90 \%$ confidence bounds, respectively. The green line represents the Markov red noise 384 spectrum. 

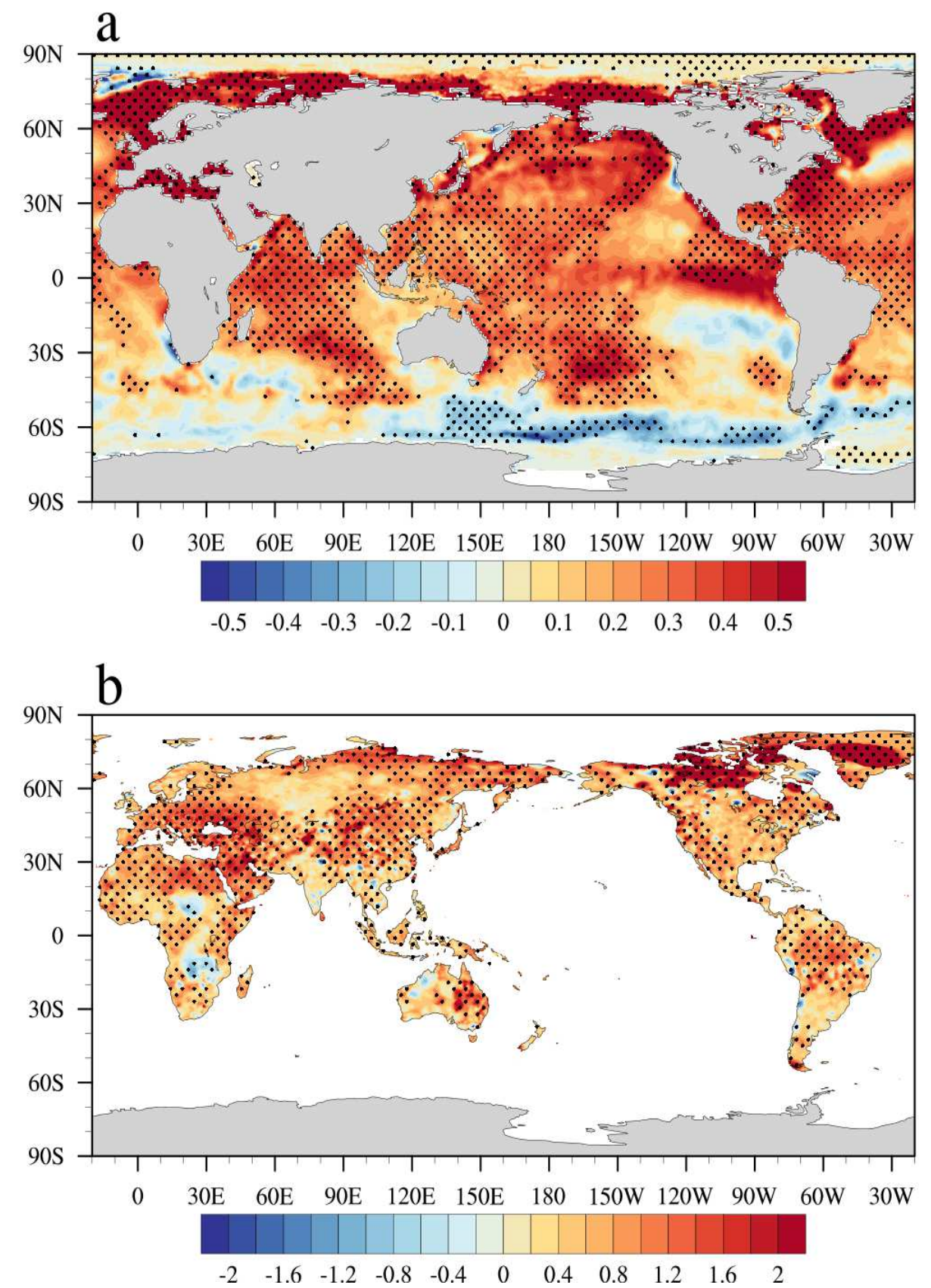

386 Supplementary Fig. 3 Characteristics of SST and land surface temperature associated 387 with the HW occurrence in JJA with a linear trend a Regressed SST anomalies against the 388 time series of HW occurrences in JJA with a linear trend. b Regressed $T_{\text {mean }}$ anomalies against the time series of HW occurrences in JJA with a linear trend. SST and $T_{\text {mean }}$ anomalies were calculated using climatology across the whole period. The unit is ${ }^{\circ} \mathrm{C}$. The black dots denote areas significant at the $95 \%$ confidence level. 


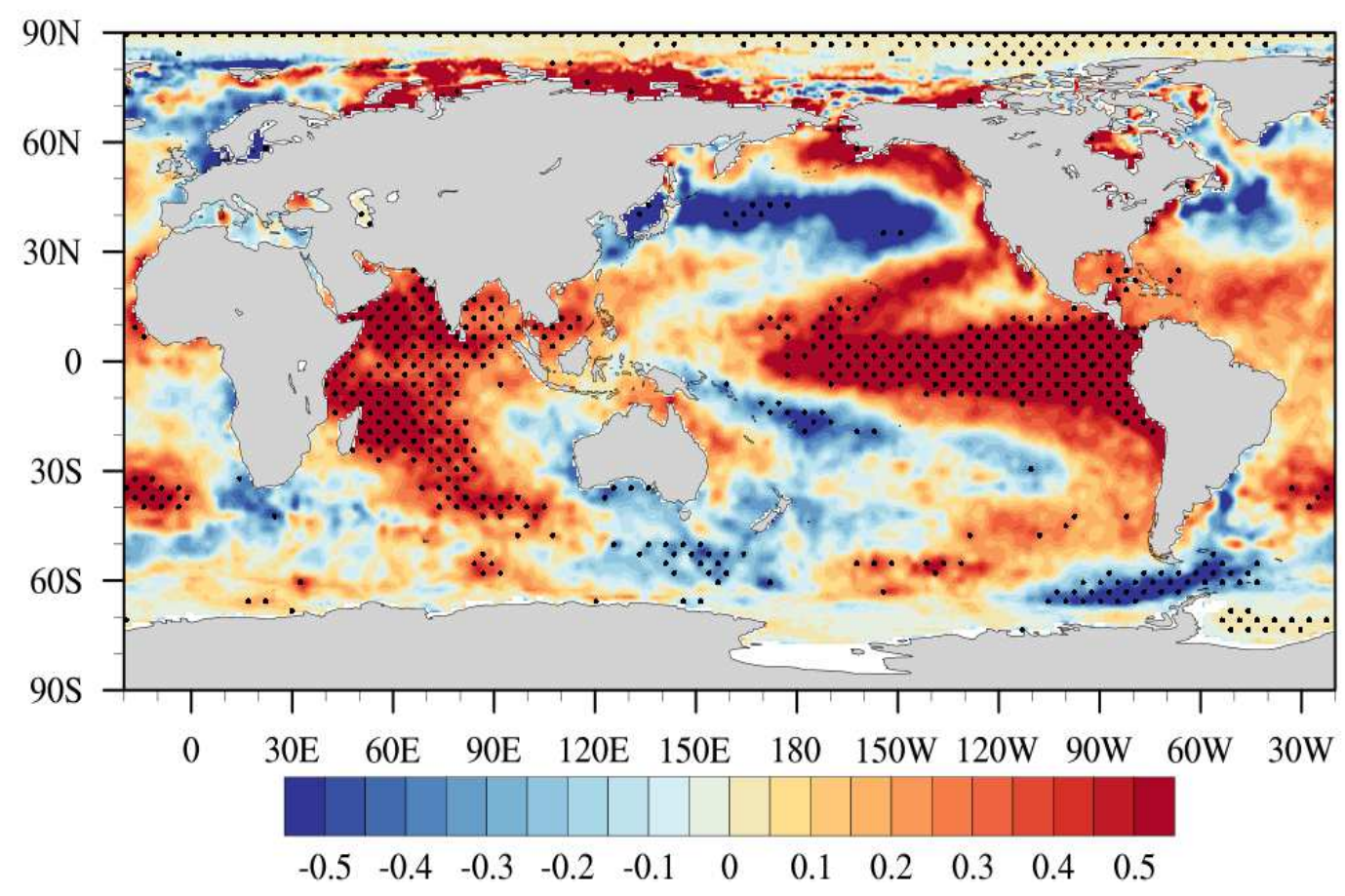

393 Supplementary Fig. 4 The spatial structure of SST anomalies associated with the HW 394 occurrence in JJA without a linear trend. Regressed SST anomalies against the time series 395 of HW occurrences in JJA without a linear trend. SST anomalies were calculated using 396 climatology across the entire period. The unit is ${ }^{\circ} \mathrm{C}$. The black dots indicate areas significant at 397 the $95 \%$ confidence level. 


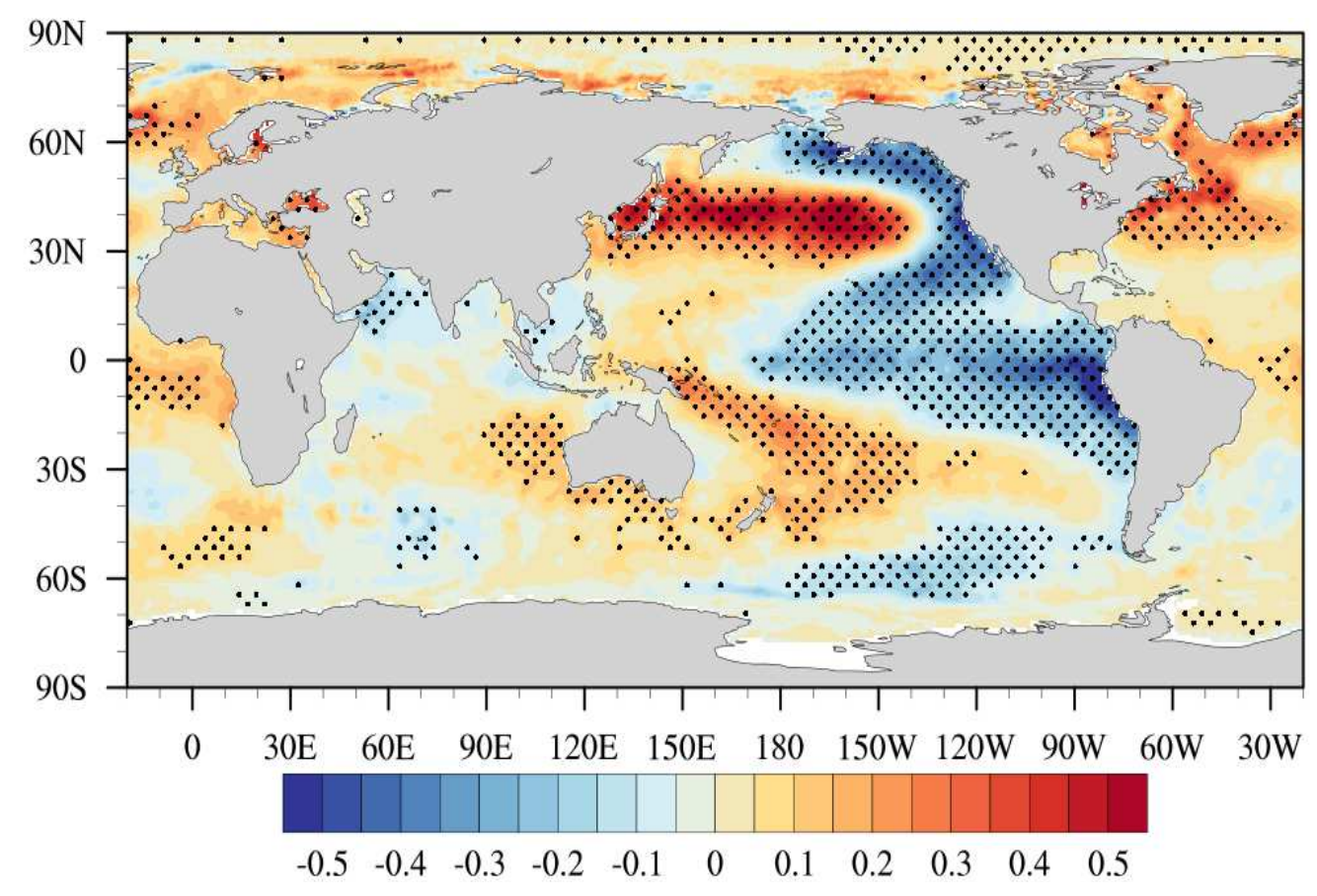

399 Supplementary Fig. 5 The PDO structure in JJA. Regression between SST anomalies and 400 the PDO index with a linear trend. The regression between the PDO index and SST anomalies 401 is for JJA from 1980 to 2018. SST anomalies were calculated using climatology from the entire 402 period. The PDO index was calculated using monthly values available from 403 http://research.jisao.washington.edu/pdo/PDO.latest.txt. The pattern is reversed to the origin. 404 The unit is ${ }^{\circ} \mathrm{C}$. The black dots indicate areas significant at the $95 \%$ confidence level. 
Regime shift index
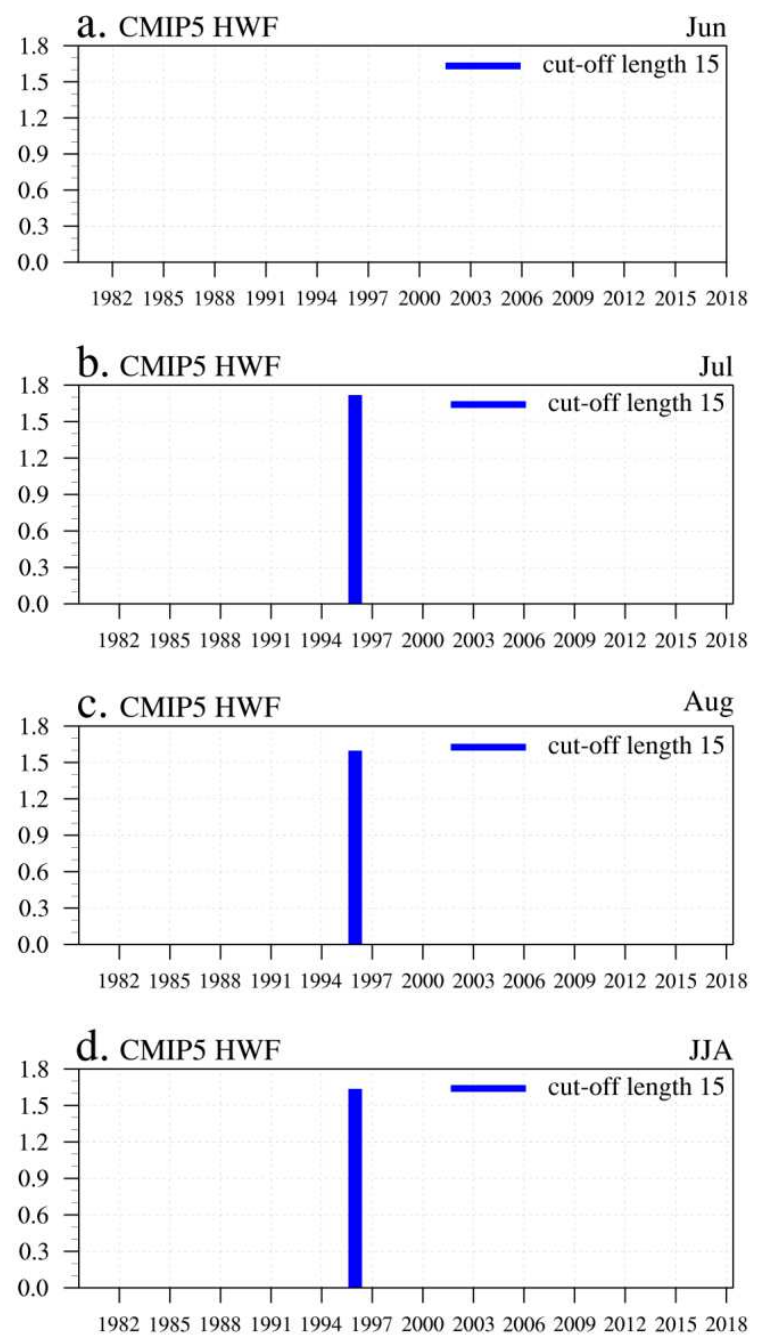

406

407

408

409

410

411

412

413

414

415 is above $99 \%$.

\section{Regime shift index}
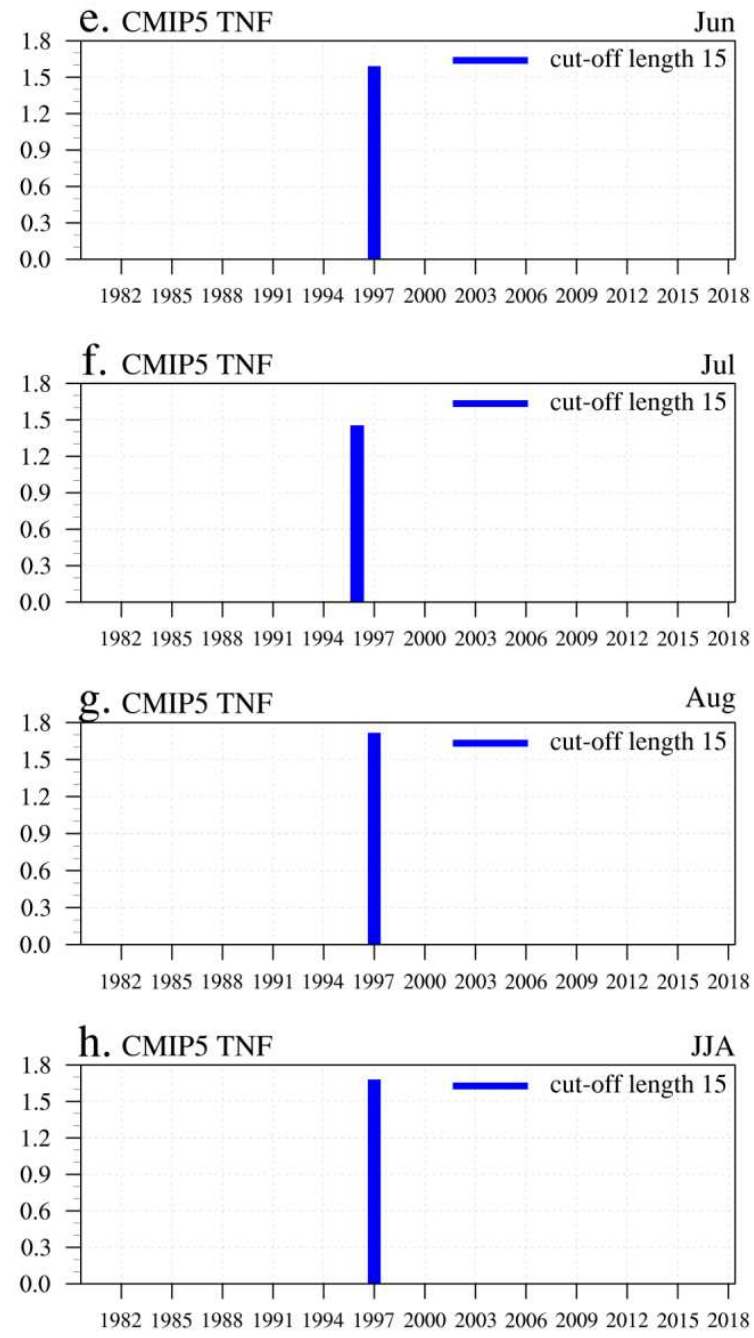

Year

\section{Supplementary Fig. 6 Regime shift analysis of ensemble mean for HW and TN frequency} in CMIP5 climate models with a cut-off length of 15. a Regime shift index of HW frequency using the ensemble mean of the CMIP5 models in June. b, c, d Same as a, but in July, August, and JJA, respectively. e Regime shift index of TN frequency using the ensemble mean of the CMIP5 models in June. f, g, h Same as e, but in July, August, and JJA, respectively. The blue bar indicates the regime shift index. In determining the regime shift, the following parameters were used: probability level of 0.05 , cut-off length set at 15 , and Huber's weight parameter of 1.0. The confidence level of the difference between the mean values of the neighboring regimes 


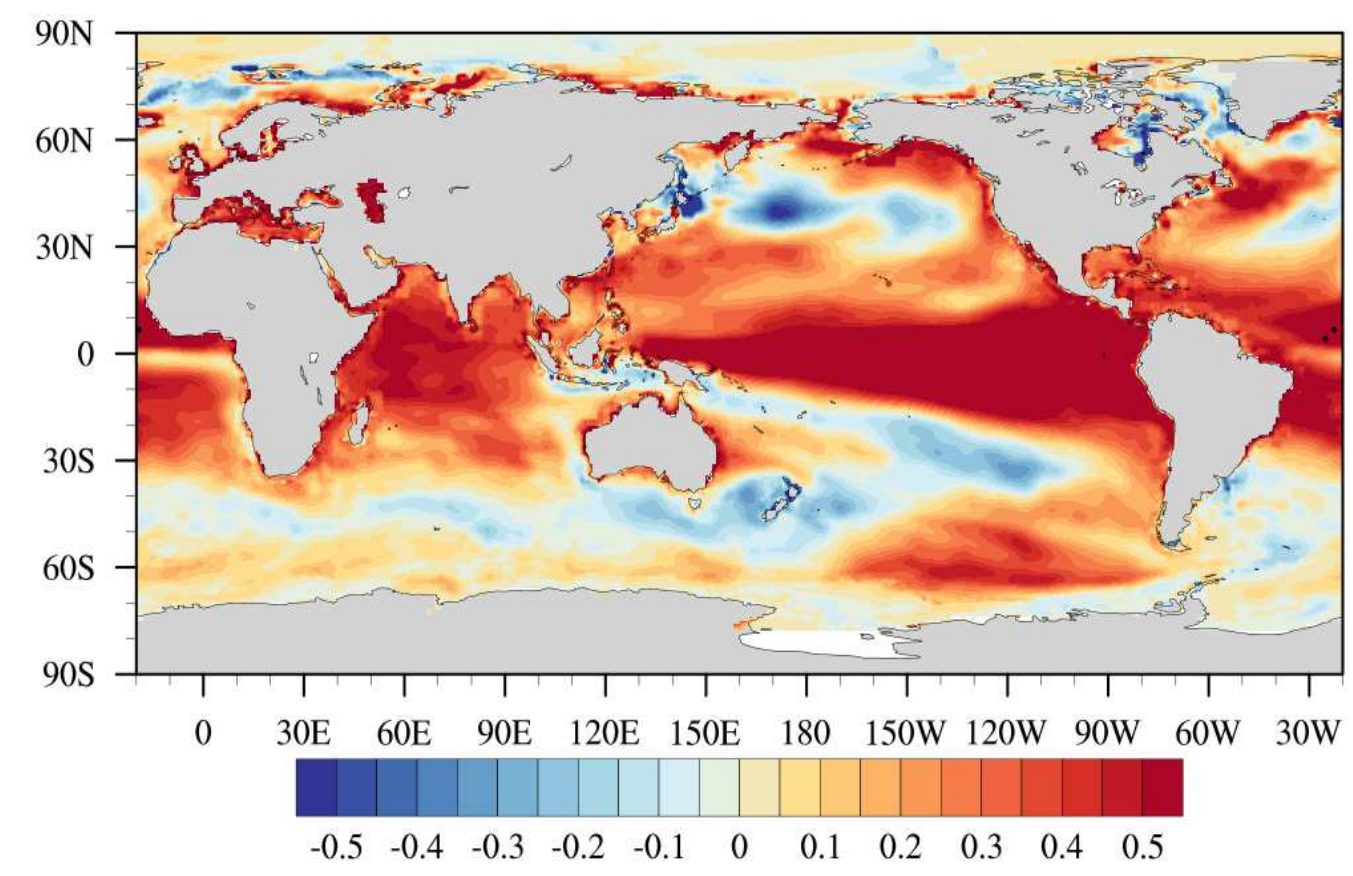

417 Supplementary Fig. 7 Regressed SST anomalies against the time series of ensemble mean 418 HWs without a linear trend. SST anomalies were calculated using climatology across the 419 entire period and averaging the individual models. The unit is ${ }^{\circ} \mathrm{C}$. The black dots denote areas 420 significant at the $95 \%$ confidence level. 
Occurence frequency of HW

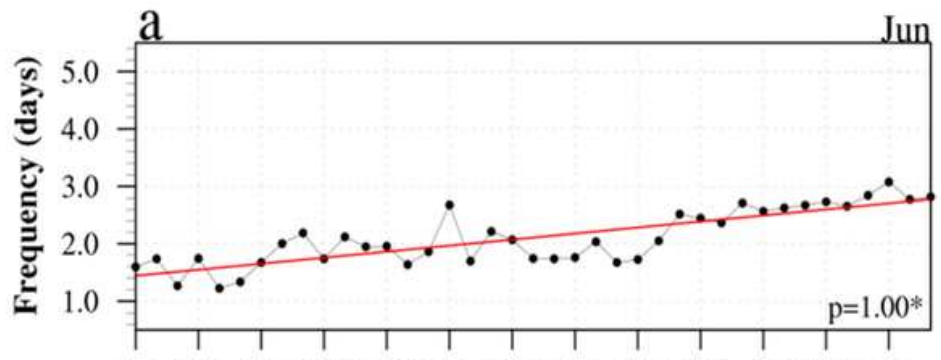

1980198319861989199219951998200120042007201020132016

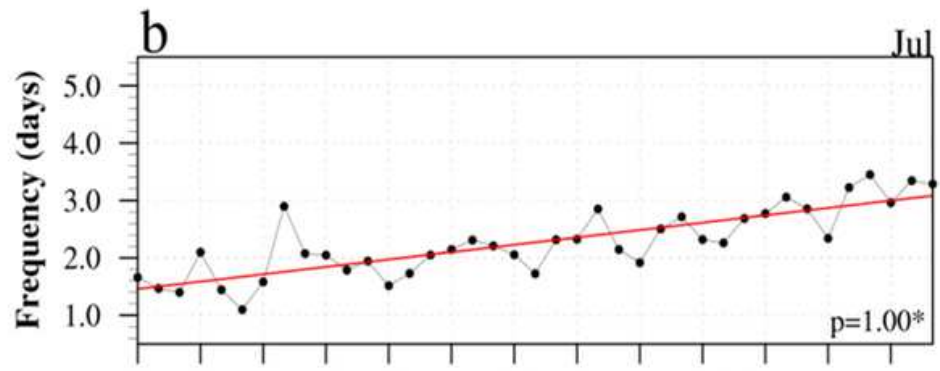

1980198319861989199219951998200120042007201020132016

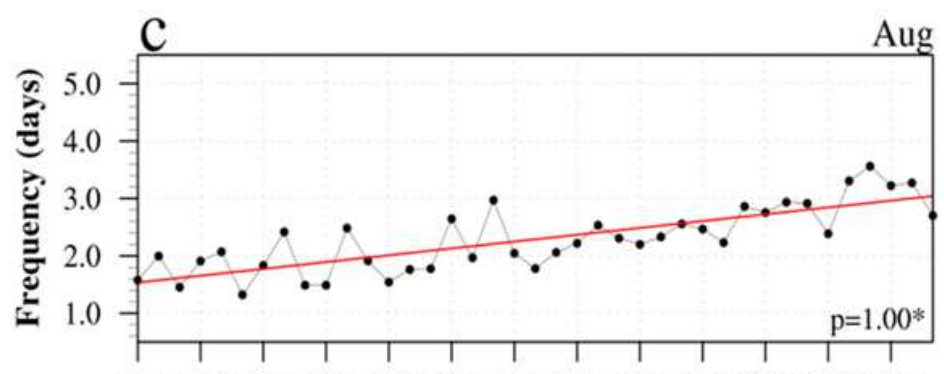

1980198319861989199219951998200120042007201020132016

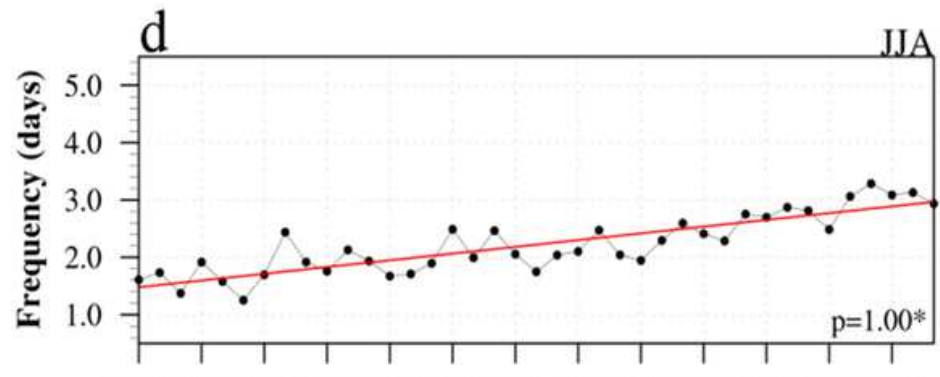

1980198319861989199219951998200120042007201020132016

Year
Occurence frequency of TN

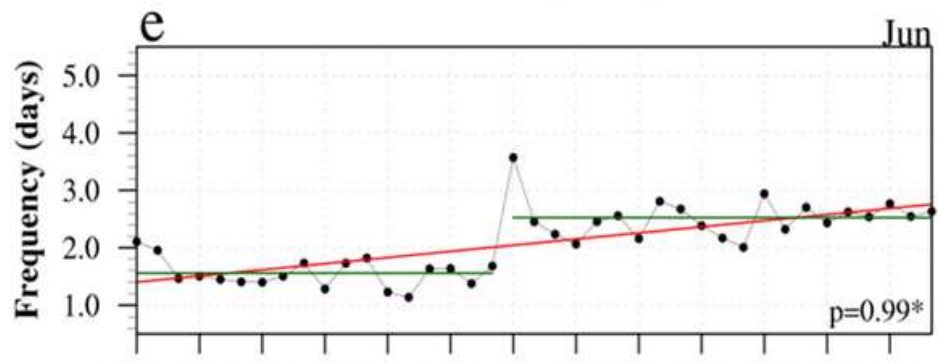

1980198319861989199219951998200120042007201020132016

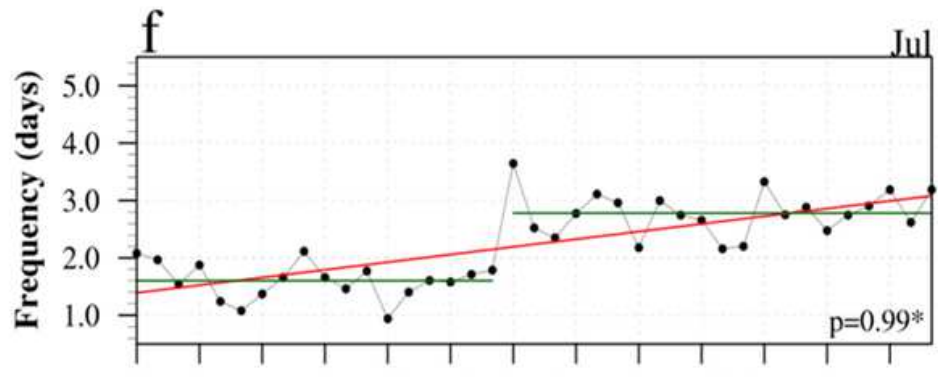

1980198319861989199219951998200120042007201020132016

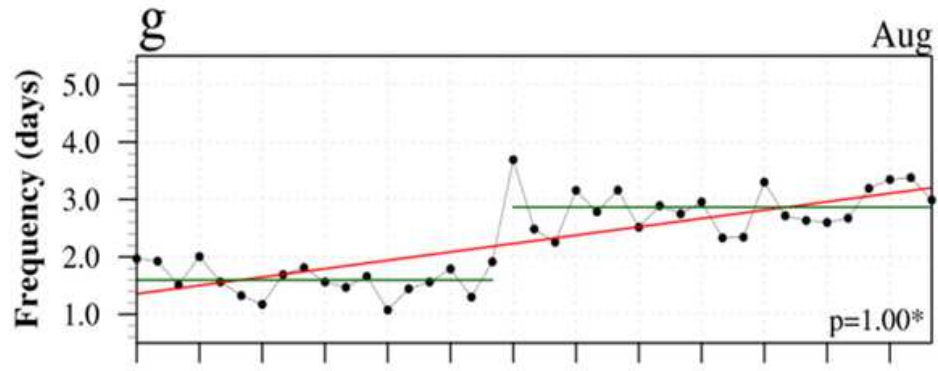

1980198319861989199219951998200120042007201020132016

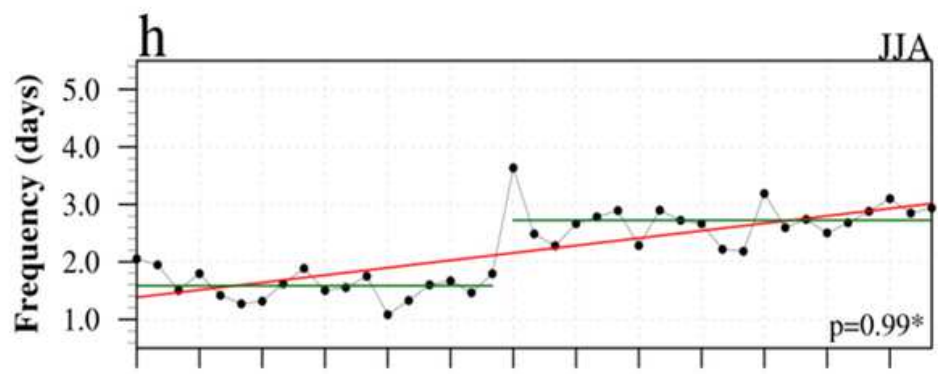

1980198319861989199219951998200120042007201020132016

Year

\section{Figure 1}

Observational time series of HW and TN occurrences. The frequency of HWs and TNs was calculated using the daily and area-weighted average in the Northern Hemisphere from 1980 to 2018. a Frequency of HWs in June. b, c, and d Same as a, but in July, August, and JJA, respectively. e Frequency of TNs in June. $f, g$, and $h$ Same as e, but in July, August, and JJA, respectively. The red line indicates a linear trend. The value in the bottom right of each figure indicates the significance probability of a linear trend. The green line denotes the mean value of the regime. 


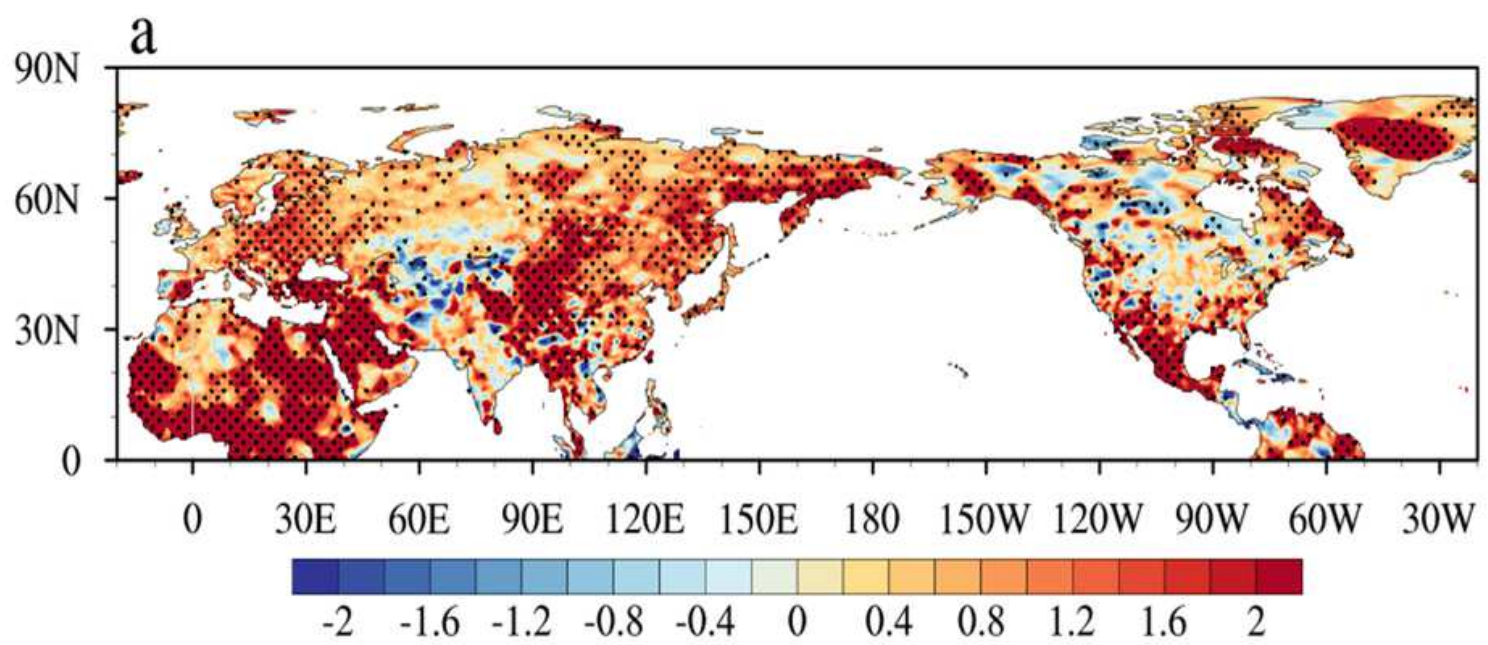

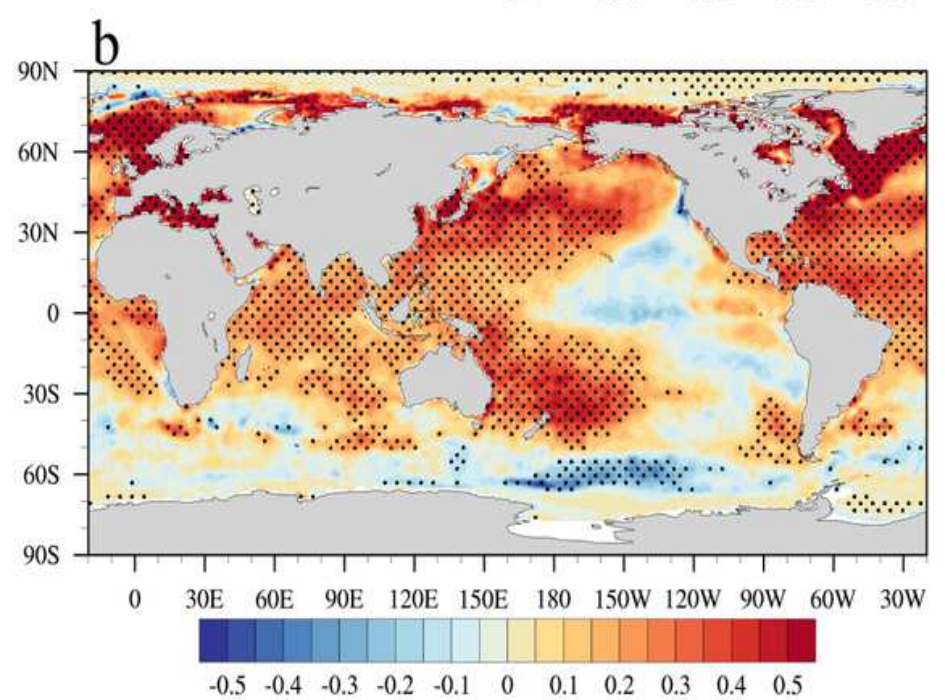

Occurence frequency of $\mathrm{TN}$

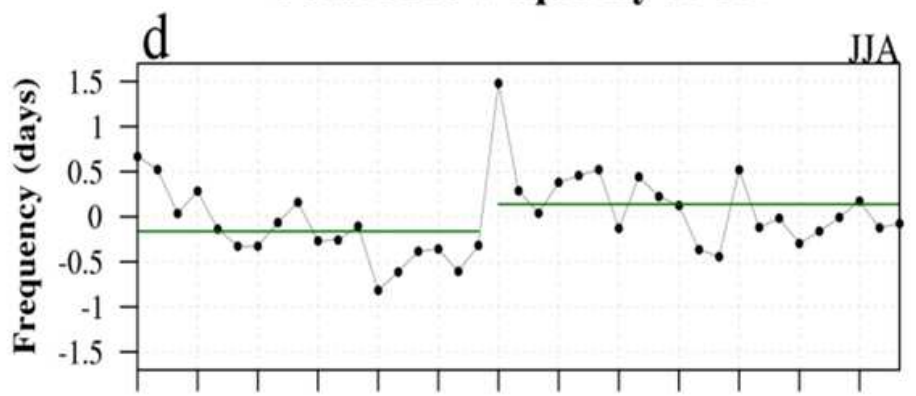

1980198319861989199219951998200120042007201020132016

Year

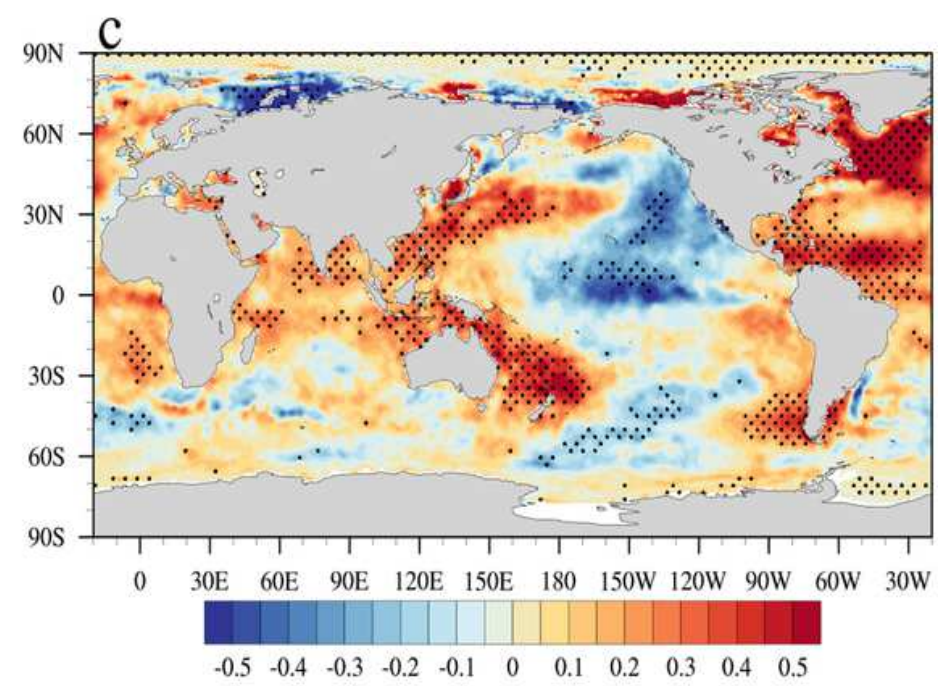

Regime shift index

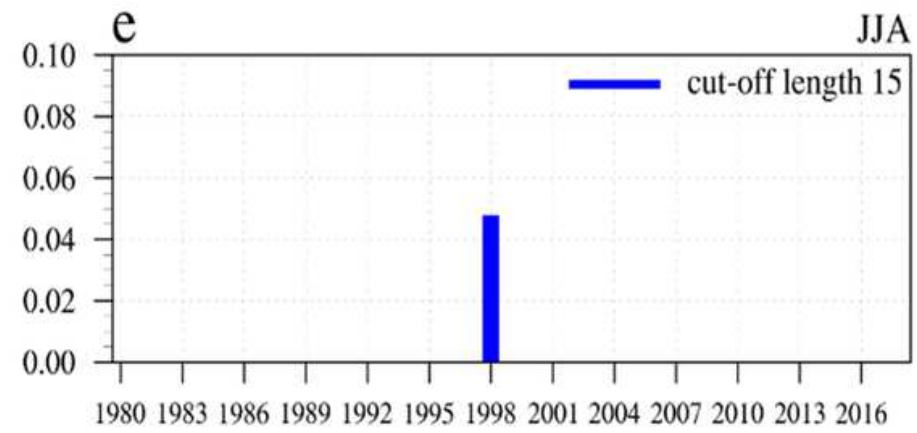

Year

\section{Figure 2}

The characteristic properties in TN occurrence frequency. a Differences in TN frequency in the Northern Hemisphere before and after the regime shift. The differences were calculated by subtracting the mean TN frequency before the regime from the mean TN frequency after the regime. The unit is day/month. b, $c$ indicate the regressed of SST anomalies against the time series of TN occurrences with and without a linear trend, respectively. SST anomalies were calculated by subtracting the climatology (1980-2018) from the raw SST dataset. Unit in b, c is पC. The black dots denote areas significant at the $95 \%$ confidence level. d observational time series of TN occurrences without a linear trend. e Regime shift 
index of TN frequency without a linear trend. In analyzing the regime shift, the following parameters were used: probability level of 0.05 , cut-off length set to 15 , and Huber's weight parameter of 1.0. The confidence level of the difference between the mean values of the neighboring regimes is above $99 \%$. Note: The designations employed and the presentation of the material on this map do not imply the expression of any opinion whatsoever on the part of Research Square concerning the legal status of any country, territory, city or area or of its authorities, or concerning the delimitation of its frontiers or boundaries. This map has been provided by the authors.

\section{Occurence frequency of $\mathrm{HW}$}
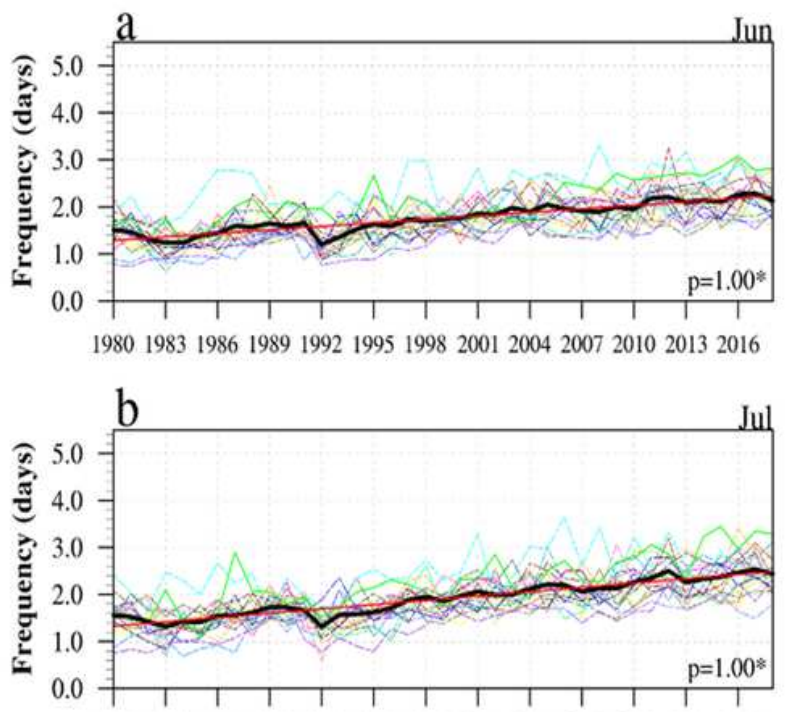

1980198319861989199219951998200120042007201020132016
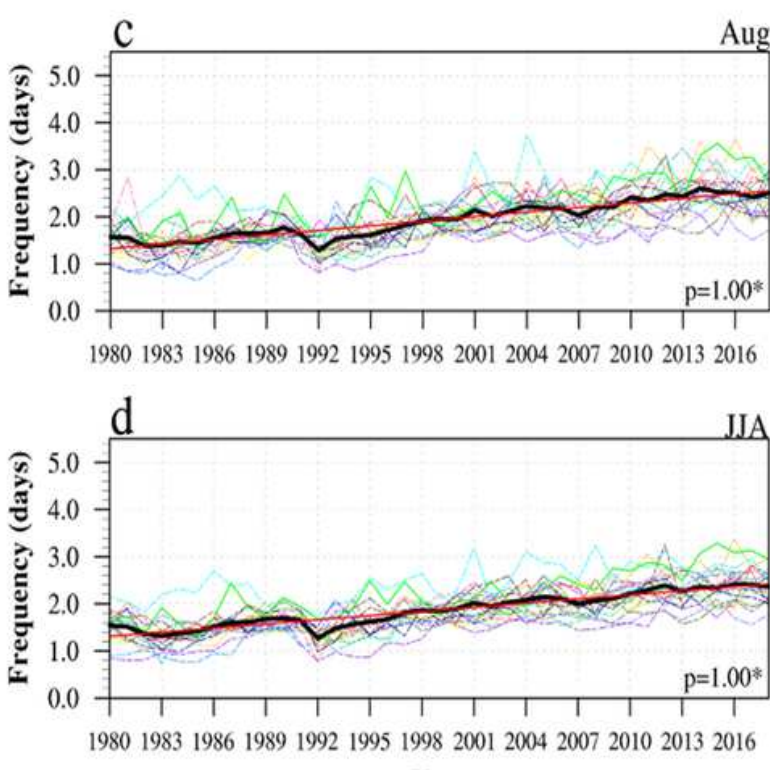

Year
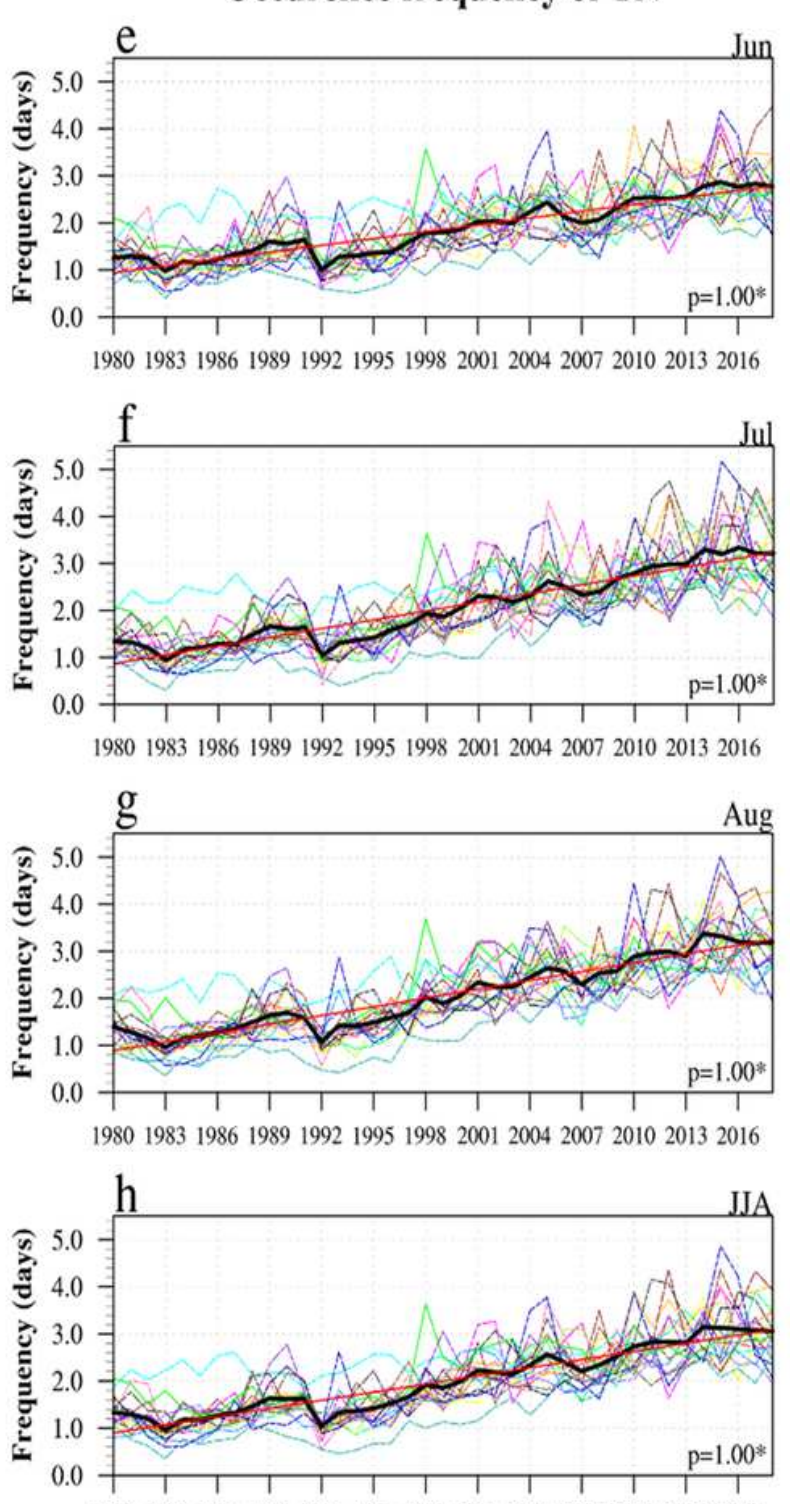

1980198319861989199219951998200120042007201020132016

Year
ACCESS1-0 ACCESS1-3 - bcc-csm1-1

-----CanCM4 CCSM4 CESMI-BGC CNRM-CM5 CSIRO-Mk3-6-0 EC-EARTH -FGOALS-g2 -GFDL-CM3

- $\mathrm{HadCM} 3$ -inmem4 -IPSL-CM5A-LR -MIROC5 -MPI-ESM-LR -MRI-CGCM3 -NorESMI-M ensemble mean observation

\section{Figure 3}

Time series of HW and TN occurrences in CMIP5 models. The frequency of HWs and TNs was calculated using daily and area-weighted averages in the Northern Hemisphere from 1980 to 2018. a Frequency of HWs in June. b, c, and d Same as a, but in July, August, and JJA, respectively. e Frequency of TNs in June. f, g, and h Same as e, but in July, August, and JJA, respectively. The black line shows the ensemble 
mean of 18 CMIP5 models. The red line indicates a linear trend of the ensemble mean. The value in the bottom right of each figure denotes the significance probability of a linear trend. The legends on the bottom right represent the individual models, ensemble mean, and observation data.
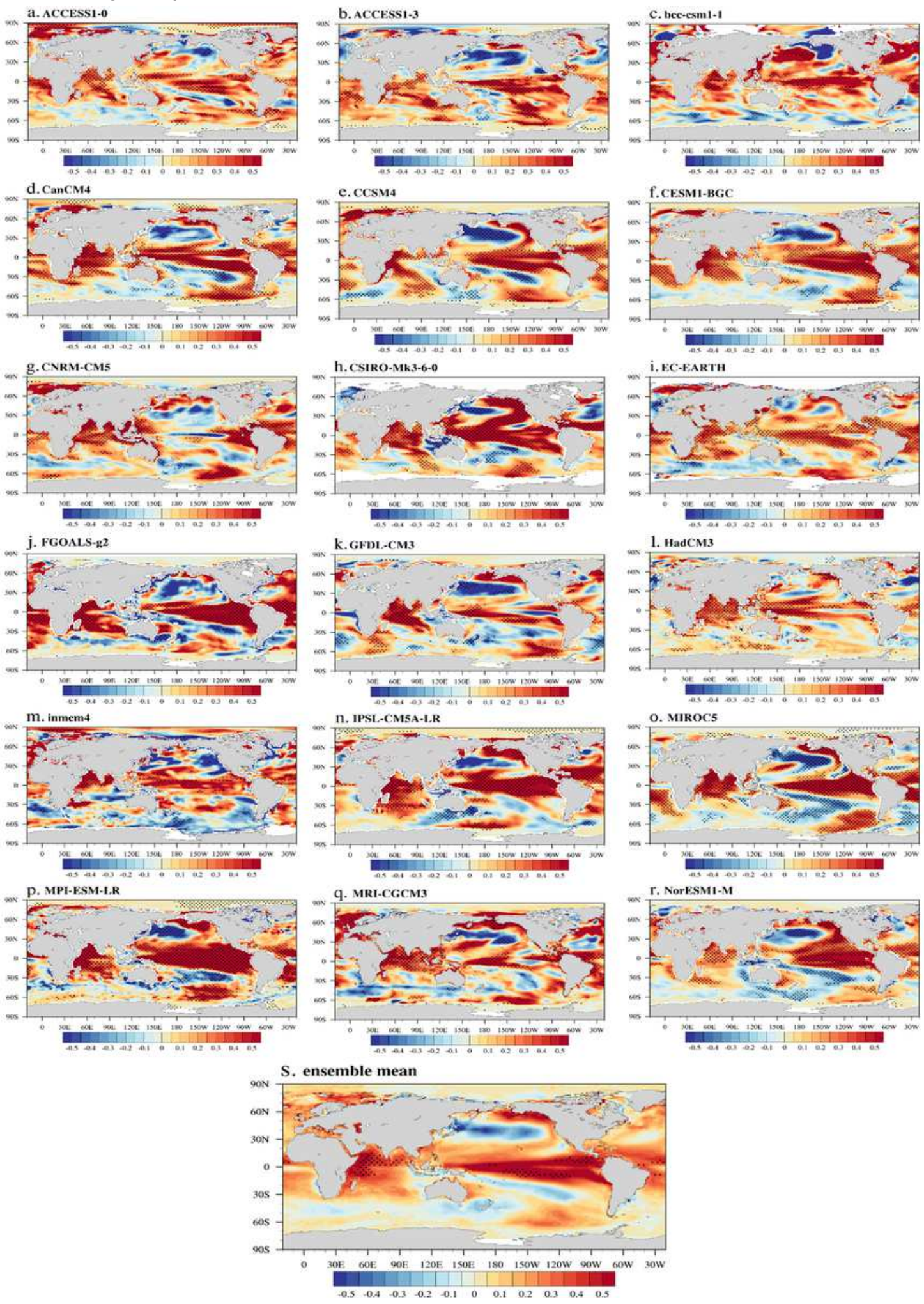

Figure 4

Regression of SST anomalies against TN frequency without a linear trend in 18 CMIP5 climate models. a The regression of SST anomalies against the time series of TN occurrences in JJA without a linear trend 
in the ACCESS1-0 model. b, c, d, e, f, g, h, i, j, k, l, m, n, o, p, q, r, s Same as a, but for ACCESS 1-3, bcc-csm11, CanCM4, CCSM4, CESM1-BGC, CNRM-CM5, CSIRO-Mk3-6-0, EC-EARTH, FGOALS-g2, GFDL-CM3, HadCM3, inmcm4, IPSL-CM5A-LR, MIROC5, MPI-ESM-LR, MRI-CGCM3, NorESM1-M, and ensemble mean, respectively. SST anomalies were calculated using climatology across the entire period in each individual

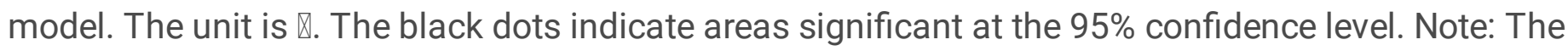
designations employed and the presentation of the material on this map do not imply the expression of any opinion whatsoever on the part of Research Square concerning the legal status of any country, territory, city or area or of its authorities, or concerning the delimitation of its frontiers or boundaries. This map has been provided by the authors. 